\title{
Development, standardization and refinement of procedures for evaluating effects of endocrine active compounds on development and sexual differentiation of Xenopus laevis
}

\author{
Ilka Lutz • Werner Kloas • Timothy A. Springer • \\ Larry R. Holden • Jeff C. Wolf • Henry O. Krueger • \\ Alan J. Hosmer
}

Received: 30 October 2007 /Revised: 7 February 2008 / Accepted: 11 February 2008 / Published online: 8 March 2008

(C) The Author(s) 2008

\begin{abstract}
Xenopus laevis has been introduced as a model to study effects of endocrine-active compounds (EAC) on development and sexual differentiation. However, variable and inconsistent data have raised questions about the reliability of the test methods applied. The current study was conducted in two laboratories to develop, refine, and standardize procedures and protocols. Larvae were exposed in flow-through systems to $17 \beta$-estradiol (E2), at concentrations from 0.2 to $6.0 \mu \mathrm{g} \mathrm{E} 2 \mathrm{~L}^{-1}$ in Experiment $1 \mathrm{~A}$, and 0.015 to $2.0 \mu \mathrm{g} \mathrm{E} 2 \mathrm{~L}^{-1}$ in Experiment 1B. In both studies survival $(92 \%, 99 \%)$ and percentage of animals that
\end{abstract}

I. Lutz $(\bowtie) \cdot$ W. Kloas

Leibniz-Institute of Freshwater Ecology and Inland Fisheries,

Mueggelseedamm 301, 12587 Berlin, Germany

e-mail: ilka.lutz@igb-berlin.de

\section{W. Kloas}

Mathematisch-Naturwissenschaftliche Fakultät I, Institut für Biologie,

Unter den Linden, 6, 10099 Berlin, Germany

T. A. Springer $\cdot$ H. O. Krueger

Wildlife International Ltd,

Easton, MD 21601, USA

L. R. Holden

Sielken and Associates Consulting, Inc.,

Bryan, TX 77802-4015, USA

J. C. Wolf

Experimental Pathology Laboratories, Inc.,

Sterling, VA 20166, USA

\section{A. J. Hosmer}

Syngenta Crop Protection, Inc.,

Greensboro, NC 27409, USA completed metamorphosis $(97 \%, 99 \%)$ indicated reproducible biological performance. Furthermore, minor variations in husbandry led to significant differences in snout-to-vent length, weight, and gonad size. In Experiment 1A, almost complete feminization occurred in all E2 treatment groups whereas a concentration response was observed in Experiment $1 \mathrm{~B}$ resulting in an $\mathrm{EC}_{50}$ of $0.12 \mu \mathrm{g} \mathrm{E} 2 \mathrm{~L}^{-1}$. The final verified protocol is suitable for determining effects of EAC on development and sexual differentiation in $X$. laevis.

Keywords Xenopus laevis Flow-through exposure system $\cdot$ Standardized protocol $\cdot$ Development .

Sexual differentiation $\cdot 17 \beta$-Estradiol

$\begin{array}{ll}\text { Abbreviations } \\ \text { ASTM } & \text { American Society for Testing Materials } \\ \text { BPA } & \text { Bisphenol A } \\ \text { DO } & \text { Dissolved oxygen } \\ \text { dpf } & \text { Days post fertilization } \\ \text { EAC } & \text { Endocrine-active compounds } \\ \text { E2 } & 17 \beta \text {-Estradiol } \\ \text { ELISA } & \text { Enzyme-linked immunosorbent assay } \\ \text { EPA } & \text { Environmental Protection Agency } \\ \text { EPL } & \text { Experimental Pathology Laboratories } \\ \text { IGB } & \text { Leibniz-Institute of Freshwater Ecology } \\ & \text { and Inland Fisheries } \\ \text { MS 222 } & \text { Tricaine methanesulfonate } \\ \text { NF } & \text { Nieuwkoop and Faber } \\ \text { WLI } & \text { Wildlife International Ltd } \\ \text { SAP } & \text { Scientific Advisory Panel } \\ \text { YAS } & \text { Yeast androgen screen } \\ \text { YES } & \text { Yeast estrogen screen }\end{array}$




\section{Introduction}

During the last ten years, the number of chemicals evaluated for endocrine-active effects has increased. Potential exposure of wildlife populations, including fish, amphibians, birds, and mammals, to environmental estrogens has attracted much attention due to the feasible impact of these substances on survival and population sustainability [1-6]. Laboratory studies using a range of wildlife species have demonstrated that physiological processes including development and reproduction, are sensitive to environmental estrogens [7, 8]. Due to the diversity of wildlife, certain species have been used as representatives of the various taxa that are considered in eco-toxicological hazard assessment. One example of a well established standardized animal model is the frog embryo teratogenesis assay (FETAX) [9] using Xenopus laevis embryos to determine impacts of chemicals on early development. This species has been investigated focusing on larval stages for studying the hormonal regulation of metamorphosis, development, sexual differentiation, and the impact of endocrine active compounds (EAC) [10-14]. However, the results in the literature for basic biological parameters such as mortality, growth, development, and sexual differentiation vary considerably among laboratories [15-17] making interpretation difficult. For example, it has been reported that the herbicide atrazine feminizes and demasculinizes amphibians [18-21] but other investigators have not been able to replicate these findings [22, 23].

The published data on potential effects of atrazine on gonadal development in laboratory studies and reproductive effects in wildlife populations were evaluated by a United States Environmental Protection Agency (EPA) Scientific Advisory Panel (SAP) in 2003. The SAP identified a number of factors that adversely affected the quality and comparability of data in the open literature on atrazine. These factors included variability in study design, differences in animal husbandry conditions (e.g., feeding rates), excess biomass in treatment chambers, and the effects of these factors on water quality. Other factors that contributed to difficulty in interpreting the results were variability in the response to the positive control substance and the negative control, as well as differences in the use of gross and microscopic pathology terminology, limited statistical power and lack of compliance with Good Laboratory Practice standards. In consequence, the SAP published a White Paper [24] that highlighted inconsistencies and variability among studies and by so doing provided guidance for the development of a standardized study design to evaluate potential effects of EAC on development and sexual differentiation of $X$. laevis.

The purpose of this study was to develop, standardize, and refine a protocol meeting specifications of the 2003 SAP that could be used to assess estrogenic effects on development and sexual differentiation in $X$. laevis. A team of scientists representing endocrinology, toxicology, chemistry, pathology, and statistics was involved in the creation of the study design, selection of endpoints, and choice of data analysis tools. The team concluded that it was necessary to conduct two independent studies consecutively in two different locations to develop, refine and validate the study design by assessing effects of E2 on gonadal development of $X$. laevis exposed from NF (Nieuwkoop and Faber) stages 46-48 through stage 66 in a flow-through exposure system. Experiment $1 \mathrm{~A}$ was conducted at Wildlife International Ltd, MD, USA (WLI) in order to develop and standardize conditions for rearing and handling $X$. laevis larvae, operation of a flow-through system and maintaining water quality and environmental parameters. A concentration range for E2 of $0.2,1.5$ and $6.0 \mu \mathrm{g} \mathrm{L}^{-1}$ was chosen to calculate the effective concentration needed to achieve a $50 \%$ effect $\left(\mathrm{EC}_{50}\right)$ for gonadal feminization and to evaluate abnormal development of gonads. In addition, this preliminary study was used to establish the terminology for classifying gross and histological gonadal abnormalities, to cross-train laboratory personnel, and to develop the appropriate statistical analysis methodology. The procedures developed in Experiment 1A were refined and, implemented in Experiment $1 \mathrm{~B}$ conducted at the Leibniz-Institute of Freshwater Ecology and Inland Fisheries, Germany (IGB).

\section{Material and methods}

\section{Test organism}

Tadpoles of $X$. laevis were obtained from the commercial supplier, Xenopus I, (Dexter, MI, USA). These larvae (approx. 1200 for each study) originated from ten pairs of adult breeders for each study. Xenopus I reared the eggs until day post fertilization (dpf) 3 and then shipped them to each laboratory.

\section{Rearing}

Upon arrival on $\operatorname{dpf} 4$, tadpoles were acclimated to water and temperature conditions $\left(21 \pm 2{ }^{\circ} \mathrm{C}\right)$ over a six-hour time period. During the acclimation period larvae were maintained in two 40-L glass aquaria containing $30 \mathrm{~L}$ well water (ca. 600 larvae/tank, Experiment 1A) and three 40-L glass aquaria containing $30 \mathrm{~L}$ dilution water (ca. 400 larvae/tank, Experiment 1B) derived from the flow-through system. At the initiation of treatment, twenty-five larvae were randomly assigned to each glass aquarium $(n=200$ larvae per treatment group) so that the biological loading rate was always less than $1 \mathrm{~g} \mathrm{~L}^{-1} \mathrm{day}^{-1}$. In Experiment $1 \mathrm{~A}$ exposures were initiated at dpf $6 \mathrm{NF}$ stage 45-46 and in Experiment 
$1 \mathrm{~B}$ at dpf 8 when tadpoles had reached NF stage $47-48$ as identified by visible hind limb buds [25]. Exposures continued until completion of metamorphosis or $\mathrm{dpf} 82$, whichever came first. Throughout the acclimation period, water temperature was recorded twice daily whereas dissolved oxygen (DO) concentration and $\mathrm{pH}$ were measured daily. Experiment $1 \mathrm{~B}$ was conducted in compliance with the local animal protection committee (G0048/05).

\section{Feeding}

Animals were fed Sera Micron (Lot No: 9698; Sera, Heinsberg, Germany), a commercially available food which was reported by the manufacturer to consist of $50.2 \%$ protein, $8.1 \%$ fat, $4.2 \%$ fibre, and $11.0 \%$ ash. A sample of Sera Micron was analysed by Lancaster Laboratories (Lancaster, PA, USA) for potential contaminants (metals and pesticides), and all tested contaminants were below their limits of quantification for analysis at that facility. A mixture of diet and dilution water was tested for estrogenicity and androgenicity using YES (yeast estrogen screen) [26] and YAS (yeast androgen screen) assays [27]. Based on these analyses no estrogenic or androgenic activity was detected.

During acclimation of larvae in Experiment 1A, $1 \mathrm{~g}$ Sera Micron was added to each tank daily. This amount of food was found to be excessive. In experiment 1B, after temperature acclimation, larvae were transferred to the acclimation tanks where they promptly attached to the glass aquaria walls. Therefore, no food was added on dpf 4 . The following day some of the tadpoles were free swimming and $150 \mathrm{mg}$ Sera Micron was added that evening by rinsing through a sieve. The amount of feed was chosen based on the intake of food by the larvae, and care was taken to ensure that feeding did not adversely affect water quality. From dpf 6 to 8 the free swimming tadpoles were fed $200 \mathrm{mg}$ Sera Micron in each tank twice a day. Throughout the remaining course of both studies, tadpoles were fed a suspension of Sera Micron $\left(77 \mathrm{mg} \mathrm{L}^{-1}\right)$ three times daily. The total quantity of food added per tank each day increased from $300 \mathrm{mg} /$ tank on $\mathrm{dpf} 8$ to $900 \mathrm{mg} / \mathrm{tank}$ on dpf 33. The quantity of food added to each tank was adjusted periodically in Experiment $1 \mathrm{~A}$ and on a daily basis in Experiment 1B to account for mortality and removal of tadpoles as they completed metamorphosis.

\section{Study design}

Because an almost completely feminized phenotype was observed in Experiment $1 \mathrm{~A}$ in all treatment groups, the nominal E2 concentrations in Experiment 1B were adjusted to $0.015,0.2$, and $1.5 \mu \mathrm{g} \mathrm{E} 2 \mathrm{~L}^{-1}$, respectively. Mid and high concentrations were selected to correspond to exper- iment $1 \mathrm{~A}$ and allow comparison of results from the two laboratories.

Replicates

Each study consisted of at least one negative control group plus three E2-treated groups, each comprising eight replicated glass aquaria/treatment groups. Eight glass aquaria were arranged in two clusters of four tanks each. The clusters of negative control tanks and E2 treated tanks were randomly distributed within the environmental chamber in Experiment 1A and within water baths in Experiment 1B. Each cluster was supplied water via the same water flow meter and mixing chamber. Experiment 1A included 16 control tanks that were initially divided into two 8-tank groups designated as negative control and reference control, respectively. The animals from all treatment groups were handled in a blinded fashion so that the biologists and histologists involved in the experiments did not know the treatment applied to frogs being observed. An additional non-blind reference control group was included to provide reference information on rates of spontaneous incidence of gonadal abnormalities for blind histological assessment of gonads from the E2 treatment groups. Histological analysis was conducted on all frogs of Experiment 1A. At the end of Experiment 1A, it was discovered that slightly elevated temperature $\left(1{ }^{\circ} \mathrm{C}\right)$ in one cluster of four negative control tanks had resulted in accelerated growth of the frogs in the tanks. Therefore, measurements of weight, length, gonad image area, and age at metamorphosis from those tanks were dropped from analysis, and the four remaining negative control tanks were combined with the reference control group to provide these measurements.

\section{Flow-through system}

Both studies were conducted using continuous flow-through systems operating at a flow rate of at least $50 \mathrm{~L}$ dilution water per tank per day. This was equivalent to a water exchange rate of approximately seven tank volumes per day. Test tanks consisted of 9-L glass aquaria $(30 \times 20 \times 14.5 \mathrm{~cm})$ containing $7 \mathrm{~L}$ water. Dilution water for Experiment $1 \mathrm{~A}$ was obtained from a well of approximately $40 \mathrm{~m}$ depth located on the WLI site. In Experiment $1 \mathrm{~B}$ the dilution water used was nonchlorinated municipal water. Dilution water samples from Experiment 1A were analysed for possible metal or pesticides by Lancaster Laboratories and water samples of Experiment $1 \mathrm{~B}$ by Environmental Chemistry and Pharmanalytics (RCC Ltd., Itingen, Switzerland).

The flow-through systems in the two laboratories were essentially identical. Prior to use, the water was passed through several filters $(5,1,0.5$, and $0.45 \mu \mathrm{m})$ to remove particulate material, a UV-sterilizer, and a final particle 
filter $(0.45 \mu \mathrm{m})$. After being filtered and temperature conditioned, the dilution water was divided into 16 streams. Each stream passed through a flow-control assembly, consisting of a rotameter flow gauge and a needle valve, to a mixing chamber. The flow from each mixing chamber was then split to supply a cluster of four tanks. Each tank received $140 \mathrm{~mL} \mathrm{~min}^{-1}$ dilution water $( \pm 5 \%)$.

Primary E2 solutions

The primary E2 stock solutions were continuously delivered to each mixing chamber $\left(0.140 \mathrm{~mL} \mathrm{~min}{ }^{-1}\right)$, where it was vigorously mixed with the dilution water. Primary E2 stock solutions were metered into the mixing chambers by an eight-channel peristaltic pump (MasterflexL/S, Model 752455, Cole-Parmer, IL, USA). The flow-through system (temperature, water, filter pressure, flow-meter), and peristaltic pumps were calibrated four weeks prior to study initiation, and inspected visually twice daily throughout the study.

\section{E2 solutions}

Once every seven days a primary E2 stock solution was prepared in amber bottles by dissolving $6 \mathrm{mg}$ E2 (Lot No: 11121AB, CAS: $50-28-2$, purity $99.9 \%$, Sigma Aldrich; WLI, Allentown, PA, USA; IGB: Taufkirchen, Germany) in alkaline solution $\left(0.01 \mathrm{~mol} \mathrm{~L}^{-1} \mathrm{NaOH}\right)$ applying moderate heating and constant mixing of the solution overnight similar to procedures employed by the Duluth Laboratory of the USEPA, Office of Research and Development (personal communication by J. Tietge). In Experiment 1A, the working stock solutions were prepared at nominal concentrations of 200, 1500, and $6000 \mu \mathrm{g} \mathrm{E2} \mathrm{L}{ }^{-1}$, and in Experiment 1B at 15, 200 , and $1500 \mu \mathrm{g} \mathrm{E} 2 \mathrm{~L}^{-1}$. The quantity of $\mathrm{NaOH}$ in $\mathrm{E} 2$ test solutions delivered to each tank was negligible, and therefore no $\mathrm{NaOH}$ was added to the negative control.

\section{Analysis of E2 concentration}

\section{Sampling}

In Experiment 1A, water samples were collected from each tank in all treatment groups to confirm the operation of the diluter two days prior to study initiation. In Experiment 1B, E2 concentrations were monitored twice weekly for a twoweek period prior to study initiation. After study initiation, water sampling was carried out twice weekly from alternating tanks in two tanks per cluster until study termination. Throughout the studies water samples were collected routinely two days after the freshly prepared E2 solution was connected to the flow-through system and a second time in the same week. At mid-depth from each test tank $190 \mathrm{~mL}$ water was collected using a glass pipette and $10 \mathrm{~mL}$ methanol $(\mathrm{MeOH})$ was added. Of this solution $20 \mathrm{~mL}$ was decanted into a $20 \mathrm{~mL}$ amber scintillation vial for E2-enzyme-linked immunosorbent assay (ELISA) analysis. The remaining volume of $180 \mathrm{~mL}$ was stored as backup at $4{ }^{\circ} \mathrm{C}$ until E2 analysis was completed. Water samples from Experiment 1B were shipped to WLI for E2 analysis. The stability of E2 was confirmed by shipping samples of E2 $\left(0.1 \mu \mathrm{g} \mathrm{E} 2 \mathrm{~L}^{-1}\right)$ that were prepared and analysed in parallel with the water samples.

Sample analysis

Rapid analysis was performed using ELISA kits (Ecologiena, Abraxis LLC, Warminster, PA, USA) to ensure the absence of the test substance in the negative control tanks and to verify the proper E2 concentration in each E2 tank. The ELISA method was based upon the E2 kit manual provided by the manufacturer. The method detection range of this assay was $0.05-0.5 \mu \mathrm{g}$ E2 $\mathrm{L}^{-1}$. Parallel analyses of water samples for E2 concentration were performed by direct aqueous injection using an Agilent Series 1100 HighPerformance Liquid Chromatograph coupled with a MDS Sciex API 3000 tandem mass spectrometer (LC-MS-MS) (Applied Biosystems, Foster City, CA, USA) and MDS Sciex API heated nebulizer ion source (Applied Biosystems) operated in the multi-reaction mode (MRM). Chromatographic separations were achieved using a Keystone Betasil C-18 column $(50 \mathrm{~mm} \times 2 \mathrm{~mm}, 3 \mu \mathrm{m}$ particle size $)$ (Thermo Hypersil, Madison, WI, USA). The method limit of quantitation (LOQ) for HPLC-MS-MS estradiol analyses was defined as $0.005 \mu \mathrm{g} \mathrm{L}^{-1}$.

\section{Environmental conditions}

Temperature

In Experiment 1A, all glass aquaria were situated in a walk-in environmental chamber $\left(21 \pm 2{ }^{\circ} \mathrm{C}\right)$. In Experiment $1 \mathrm{~B}$, glass aquaria were placed in temperature controlled water baths $\left(22 \pm 1{ }^{\circ} \mathrm{C}\right)$. In both experiments water temperatures were continuously recorded, and temperatures in all glass aquaria were measured weekly using a liquid-in-glass thermometer.

Light

The target light intensity at tank level was 100-500 lux and was measured weekly using a Sper Scientific (AZ, USA) light meter. A photoperiod of $16 \mathrm{~h}$ of light and $8 \mathrm{~h}$ of dark was used in Experiment 1A, and was adjusted to a $12 \mathrm{~h}$ 
light, 12 h dark cycle in Experiment 1B. A 30-min low light (around 30\% intensity of full light) transition period was installed in both laboratories.

\section{Water quality}

Water quality parameters were assessed according to ASTM (2003) [28] and US EPA guidelines. Water hardness, $\mathrm{pH}$, conductivity, and the concentrations of nitrate, and ammonia were measured weekly in one tank from each cluster throughout the experiments. Hardness and alkalinity were measured by titration based on procedures described in "Standard Methods for the Examination of Water and Wastewater" [29]. Nitrate concentrations were analysed with a Hach DR/700 colorimeter (Hach Company, Colorado, USA) and specific conductance was detected using a YSI conductivity meter (WLI: Yellow Springs Instruments Model 33, IGB: 3200, Yellow Springs, $\mathrm{OH}, \mathrm{USA}) \cdot \mathrm{pH}$ and ammonia concentrations were measured with an Orion pH/ISE Meter 720Aplus (Thermo Electron, USA). DO concentrations were measured in alternate tanks per treatment three times a week with an Orion Model 850plus dissolved oxygen meter (Thermo Electron). Commencing at dpf 43 in Experiment 1A, and at dpf 36 in Experiment 1B, gentle external aeration was applied by a glass pipette in each test tank to ensure maintenance of an adequate DO concentration.

\section{Maintaining water quality}

The tanks required daily cleaning to minimize microbial growth and to maintain adequate water quality. Bio-film that accumulated on the inner walls and bottom of the tanks was scraped off daily, and detritus was siphoned from the tanks. Daily cleaning proved inadequate to maintain appropriate water quality throughout the entire exposure period. Hence, in Experiment 1A all tanks were replaced with clean tanks weekly and in Experiment 1B twice throughout the experiment when siphoning did not lead to satisfactory results.

\section{In-life assessment of tadpoles}

Tadpoles were monitored for changes in general health, swimming behaviour and morphological appearance daily. The numbers of dead or moribund tadpoles and tadpoles completing metamorphosis were recorded daily for each tank.

Snout-to-vent length and weight

Each tadpole that had either completed metamorphosis by NF stage 66, or had failed to achieve metamorphosis by dpf 82 , was removed from the test tank and euthanized by immersion in MS 222 (tricaine methanesulfonate) (WIL: Sigma Aldrich, Allentown, PA, USA; IGB: Sigma-Aldrich, Taufkirchen, Germany) ( $2 \mathrm{~g} \mathrm{~L}^{-1}$ buffered to $\mathrm{pH} 7.5$ with $\mathrm{NaHCO}_{3}$ ). Immediately thereafter, the snout-to-vent length was measured to the nearest millimetre. Each frog was blotted dry and then weighed to the nearest milligram. A unique identifier was assigned to each frog that included: study number, in-life laboratory ID, colour code, replicate, and animal number.

\section{Gross pathology}

The pleuroperitoneal cavity was opened to expose the visceral organs. The liver, stomach, and intestine were examined using a dissecting stereo microscope (WIL: Olympus SZ61-TR, Olympus America, Melville, NY, USA; IGB: Olympus, SZX7, Olympus, Hamburg, Germany), and unusual variations in size, colour, and/or abnormal structure were recorded. The gastrointestinal tract was excised to expose the ventral surfaces of the kidney and gonads, which were similarly assessed for gross abnormalities. Tadpoles that did not complete metamorphosis at study termination (Experiment 1A: 25, Experiment 1B: 7) were staged according to NF and, the gonad morphology was assessed (if possible), and the carcasses were archived in fixative. Data derived from such animals were excluded from further analysis.

Assessment of gonad morphology

Using a dissecting stereo microscope, gross evaluations of gonad morphology were performed on all animals that reached NF stage 66. To enhance visualization of the gonads, which presented as thin, pale-tan strips of tissue on the ventromedial margin of the kidney, several drops of Bouin's solution (WIL: Sigma Aldrich, Allentown, PA, USA; IGB: Sigma-Aldrich, Taufkirchen, Germany) were applied to partially fix these organs. Based on gross observation, the gonads of each animal were identified as testes, ovaries, or malformed. Examples of observed malformations included mixed sex, intersex, pearling and segmental aplasia. Mixed sex was defined as the cooccurrence of both ovarian and testicular tissue in a single gonad. Intersex was assessed as ovarian and testicular tissue in the same individual as separate gonads (left/right). The term pearling was characterized by the presence of multiple, prominent segmental enlargements and/or attenuations along the length of one or both gonads, whereas gonads that presented as nodular islands of testicular or ovarian tissue, with either intervening membranous connections or no connections at all, were classified as segmental aplasia. Gross findings for the gonads of each frog were recorded separately for the left and right gonads. 
The gonadal findings for each frog were verified independently by a second biologist. If the two biologists differed in their interpretations, the disparate opinions were discussed and a consensus finding was recorded.

Prior to the initiation of the first E2 experiment a list of standardized terms for changes of potential morphological gonadal observations was developed. Subsequent to the completion of both experiments the applied terminology was refined in order to better characterize and group different types of gonad changes observed and which in turn could be analysed. For example, the subcategories narrow, slightly narrow, truncated, slightly truncated, and margin entire were integrated into the main category hypoplasia. This term describes all gonads which appear smaller than those characterised as "typical/normal". Since the term "typical/ normal" is rather general, further sub-categories allow the biological variability of gonadal morphology to be described. However, during the investigations it was revealed that too few observations in each sub-category ruled out reasonable statistical analyses. Therefore, a refined list of qualitative descriptive terminology for gonadal features was created as presented in Table 1.

\section{Photography}

After gross gonad inspection was complete, each gonad was photographed in situ using a digital camera (WIL: Olympus DP12-2, Olympus America, Melville, NY, USA; IGB: Olympus DT5, Hamburg, Germany) attached to the stereo microscope. Each digitalized image included a millimetre measurement scale placed adjacent to the gonads to permit gonad size to be determined from the photograph. Following photography, each frog was placed in a labelled individual container of $30 \mathrm{~mL}$ of Bouin's solution for approximately $48 \mathrm{~h}$. At the end of the fixation period, each carcass was rinsed several times in $70 \%$ ethanol and was placed in $30 \mathrm{~mL} \mathrm{10 \%} \mathrm{neutral} \mathrm{buffered} \mathrm{formalin} \mathrm{(WIL:}$ VWR, Westchester, PA, USA; IGB: Histofix, Roth, Karlsruhe, Germany). A complete gonadal histological evaluation was performed on each frog of experiment $1 \mathrm{~A}$ and results are presented in a separate paper (Wolf et al., in preparation). In some cases the growth and histological findings differ and a better understanding of results is gained by considering both types of observation.

\section{Gonad measurement}

The biological variability of morphological features of the gonads and the subjective nature of the assessment prompted us to develop a more quantitative metric of gonad size. Thus, individual measurements of gonad image area were derived from photographs of the gonads. Gonad image areas were obtained using image-processing software
(Image Pro Plus, Version 5.1, Media Cybernetics, Silver Spring, MD, USA) that calculated the combined area of the left and right gonad whose outline had been manually traced around the digital image. The program was calibrated by the millimetre measurement scale prior to measurement for the gonad of each tadpole.

\section{Statistical analysis}

For both experiments, observations were collected for each animal. However, consistent with the experimental design, the tank is considered the primary experimental unit. When tank differences are present, statistical analysis should accommodate this experimental structure directly using nested "random effects" analyses or indirectly by analysing tank means or tank percentages. Neither approach is completely satisfactory for all endpoints. Nested models have specific distributional requirements and, in the case of incidence data, become unstable when frequencies are at or near zero. Analyses of tank means can also be problematic for these experiments. Estradiol-induced feminization causes the number of males per tank to be smaller for treated groups than for the control group. This, in turn, results in greater variation between estradiol-treated tanks than between control tanks. Most parametric and nonparametric statistical procedures, however, require equal variability between tanks within every group. When tank differences are small or absent, however, the individual data from all tanks within the same treatment group can be pooled and analysed more simply using the frog as the basic experimental unit.

For Experiments $1 \mathrm{~A}$ and $1 \mathrm{~B}$, endpoints were tested for differences between tanks using a test of homogeneity. A chi-square homogeneity test was used for frequency endpoints (males, females, mixed sex) and a Kruskal-Wallis test was used for measurement endpoints (snout-to-vent length, body weight, age at completion of metamorphosis, gonad image area). This homogeneity test was calculated for each experimental group and the $p$-values combined using Tippett's minimum- $p$ method. Tank differences were found for several frequency endpoints in Experiment 1A. In addition, there was evidence that the presence of a humidifier caused a temperature-induced impact on measurement endpoints for two clusters of tanks. In contrast, Experiment 1B did not reveal any statistically significant $(p<0.05)$ tank effects. Consequently, all subsequent statistical analyses for Experiment 1B can be conducted on individual animals with all tanks pooled. Thus, analyses of Experiment $1 \mathrm{~A}$ are quite complex and varied while Experiment 1B results can be analysed rather simply. In order to summarize the results consistently to allow comparisons of both experiments, only animal-level means and standard 
Table 1 Glossary of terms used to describe features observed during gross morphological examination of gonads in $X$. laevis NF stage 66

Feature Definition

1. Adhesion (other tissue)

2. Aplasia (agenesis)

3. Segmental Aplasia 3-A. Tissue separation

3-B. Extraneous gonadal tissue

4. Bifurcation

4-A. Protuberance(s)

4-B. Symmetric

5. Angular deformity

5-A. Gonad folded

6. Displaced

6-A. Displaced laterally

6-B. Displaced medially

6-C. Displaced cranially

6-D. Displaced caudally

7. Fused

8. Hypertrophy

8-A. Wide

8-B. Elongated

8-C. Thick

8-D. Enlarged

9. Segmental hypertrophy

9-A. Enlargement (mass)

9-B. Pearling

9-C. Partly thick

10. Hypoplasia

10-A. Narrow

10-B. Slightly narrow

10-C. Truncated

10-D. Slightly truncated

10-E. Thin

10-F. Margin entire

11. Segmental hypoplasia

11-A. Partly narrow

11-B. Partly thin

11-C. Margin slightly sinuate

11-D. Margin partially

entire

11-E. Pearling

12. Intersex

13. Mixed sex

14. Translucent

14-A. Tissue slightly

translucent

15. Segmental translucence

16. Melanophores decreased
Gonads joined to other abdominal tissue

Complete lack of gonad development

Gonad is longitudinally discontinuous

One or more areas along the length of the gonad is poorly developed, attenuated with an essentially complete lack of gonadal tissue

A small disjunct cluster of gonad-like tissue

Division of the gonad oriented longitudinally, along the cranial-caudal axis

Small projection(s) of the gonad along the margins

A "Y" -shaped single gonad with relatively equal division

One or more bends in the gonad to an excessive degree

The gonad is bent over or doubled up so that one part lies on another

The gonad, or a section of it, is not located in the typical location

The gonad, or a section of it, is not located in the typical location. Instead it is located further away from the frog's midline

The gonad, or a section of it, is not located in the typical location. Instead it is located closer to or crosses over the frog's midline

The gonad is not located in the typical location. Instead it is located more towards the anterior

The gonad is not located in the typical location. Instead it is located more towards the posterior

Left and right gonads joined to varying degrees at one or more locations along cranial-caudal axis

Size of the gonad is larger than typical

Gonad appears broad. Lateral width is large relative to the length

Gonad appears long (cranial-caudal). Length is large relative to the length of the kidneys and the torso of the frog

Gonad relatively increased in the distance between the dorsal and ventral surfaces

A generalized increase in the size of the gonad along all axes

A gonad where one or more areas are excessively large

A section of the gonad substantially bigger in width and/or thickness than the remaining tissue

Pronounced multiple segmental enlargement of the gonad

A section or sections of the gonad is relatively increased in the distance between the dorsal and ventral surfaces

Size of the gonad is decreased

Gonad appears strap-like. Lateral width is markedly reduced relative to the length

Lateral width is somewhat reduced relative to the length

Gonad appears short (cranial-caudal). Length is small relative to the length of the kidneys and the torso of the frog

Gonad appears somewhat short (rostal-caudal). Length is somewhat reduced relative to the length of the kidneys and the torso of the frog

Gonad relatively reduced in distance between the dorsal and ventral surfaces

All of the ovary or indeterminate gonad has a smooth edge; no scalloping or lobes

A gonad where one or more areas are excessively reduced, attenuated, or poorly developed but not separated

A section or sections of the gonad has a small lateral width relative to the length and the width of the other sections

A section or sections of the gonad is relatively reduced in distance between the dorsal and ventral surfaces

Gonad has only shallow waved or scalloped edge (typically associated with a narrow or partly narrow ovary)

A section or sections of the gonad has a smooth edge (typically associated with a narrow or partly narrow ovary)

Pronounced multiple segmental attenuation or narrowing of the gonad

Ovarian and testicular tissue present as separate structures (i.e. not contained in the same gonad) (left/right)

Ovarian and testicular tissue present in the same gonad

Gonad appears not so dense, light able to pass through diffusely

To a small extent the gonad appears not so dense, a small amount of light able to pass through diffusely

A section or sections of the gonad appears not so dense, light able to pass through diffusely

Apparently fewer pigment-containing cells than typically seen. Applies only to females, mixed sex frogs, and frogs of undetermined sex 
Table 1 (continued)

\begin{tabular}{ll}
\hline Feature & Definition \\
\hline 16-A. Apigmentation & $\begin{array}{c}\text { No melanophores in the internal tissue. Applies only to females, mixed sex frogs, and frogs of undetermined } \\
\text { sex } \\
\text { Pigment-containing cells within the gonadal tissue. Applies only to males, mixed sex frogs, and frogs of } \\
\text { undetermined sex } \\
\text { Any finding not listed. Describe as needed. For any "other" finding that study personnel consider not } \\
\text { incidental, notify the Study Director and other laboratories as soon as possible via email including a } \\
\text { description and photograph }\end{array}$ \\
\hline
\end{tabular}

deviations are presented. The means and standard deviations given in this report for both experiments were calculated from individual animals using Excel Version 2000. For Experiment $1 \mathrm{~B}$ these simple statistics are identical with those obtained from the statistical analyses described below. For Experiment 1A these means (and standard deviations) should be considered only approximate. They may differ slightly from means obtained using more sophisticated analyses that incorporate a tank structure.

In Experiment 1B, the estradiol-treated groups were compared with controls in a step-wise manner that preserved power and protected against excessive false positives. An overall test of group differences and a test for trend with dose were both conducted. If either of these two overall tests showed statistical significance at the $5 \%$ level (i.e., $p<0.05$ ) then comparisons of each dose group to the control were made. For frequency endpoints a chi-square homogeneity test and a Cochran-Armitage test for trend were used for the overall homogeneity and trend tests, respectively. Comparisons of dose groups to control were conducted using Fisher's exact test. For measurement data essentially all endpoints showed statistically significant deviations from normality ( $p<0.01$, Shapiro-Wilk test). Consequently, a Kruskal-Wallis nonparametric test was used for group homogeneity and a Jonckheere-Terpstra test was used for trend. Comparisons of dose groups to control were conducted using the nonparametric Wilcoxon-Mann-Whitney U-test. All statistical analyses of Experiment 1B were calculated using Release 9.1 of the SAS statistical package (2004).

\section{Results}

It is emphasized that Experiment 1A was performed first in order to standardize conditions for rearing $X$. laevis and for operation of the flow-through system. Improvements of these procedures were implemented in Experiment 1B resulting in optimised growth and development conditions for $X$. laevis tadpoles. Those parameters that were successfully achieved during Experiment $1 \mathrm{~B}$ are summarised in
Table 2 and may be used as guidance for similar experiments. The following sections focus on results obtained in Experiment 1B, presenting results from Experiment 1A, as needed, to allow comparison of the two experiments.

\section{Environmental conditions}

In both experiments experimental conditions generally met the criteria listed in Table 2. In Experiment 1B the mean and SD for hardness and alkalinity were $103 \pm 5.8 \mathrm{mg}$ and $162 \pm$ $6.8 \mathrm{mg} \mathrm{CaCO}_{3} \mathrm{~L}^{-1}$, respectively. Specific conductance was $794 \pm 18.0 \mu \mathrm{S} \mathrm{cm}^{-1}, \mathrm{pH} 8.1 \pm 0.09$, nitrate $1.6 \pm 0.5 \mathrm{mg} \mathrm{L}^{-1}$ and ammonia $0.08 \pm 0.09 \mathrm{mg} \mathrm{L}^{-1}$. The measurements from negative control tanks were not significantly different from those from the E2 tanks. Technical problems in Experiment $1 \mathrm{~B}$ prevented accurate determination of DO concentration, however, based on subsequent studies using the same procedures, DO was consistently above $60 \%$ saturation.

\section{E2 exposure verification}

In each experiment, E2 was not present in any of the negative control tanks. Measured concentrations of E2 stock solutions ranged from 96.6 to $106 \%$ in Experiment $1 \mathrm{~A}$ and between 90.5 and $108 \%$ in Experiment 1B. In Experiment 1A, the mean concentration of E2 for three treatment groups began to decline after experiment initiation and fell below $80 \%$ of nominal E2 concentration by dpf 29. Between exposure dpf 43 and 50 mean concentration of E2 decreased to minima of $0.4,43$, and $38 \%$ of nominal concentrations of E2 in the $0.2,1.5$, and $6.0 \mu \mathrm{g}$ E2 $\mathrm{L}^{-1}$ treatment groups, respectively. After dpf 50, concentrations of E2 began to increase in all treatment groups, and exceeded $60 \%$ of nominal concentration on dpf 64 (Fig. 1a). In Experiment 1B, concentrations of E2 declined after study initiation and dropped below $60 \%$ of nominal E2 concentration by dpf 23. On dpf 37 concentrations of E2 fell to 47,46 , and $50 \%$ in the $0.015,0.2$, and $1.5 \mu \mathrm{g} \mathrm{E} 2 \mathrm{~L}^{-1}$ treatment groups, respectively. The concentration of E2 increased to $60 \%$ of nominal concentration on dpf 65 (except the $1.5 \mu \mathrm{g} \mathrm{E} 2 \mathrm{~L}^{-1}$ with 44.4\%) (Fig. 1b). 
Table 2 Final study design specifications. Brief summary of the most important parameters for exposing $X$. laevis tadpoles in a flow-through exposure system

\begin{tabular}{|c|c|}
\hline Parameter & Characteristic \\
\hline \multicolumn{2}{|l|}{ Water-quality parameters } \\
\hline Supply water: filtered, contaminant free & Filtered and UV sterilized; tested for chemical contaminants \\
\hline Dissolved oxygen & $\geq 60 \%$ of saturation \\
\hline $\mathrm{pH}$ & 7.9 to 8.3 \\
\hline Ammonia & 0.0 to $0.35 \mathrm{mg} \mathrm{L}^{-1}$ \\
\hline Nitrate & 0.04 to $2.29 \mathrm{mg} \mathrm{L}^{-1}$ \\
\hline Hardness & 90 to $130 \mathrm{mg} \mathrm{CaCO}_{3} \mathrm{~L}^{-1}$ \\
\hline Alkalinity & 133 to $172 \mathrm{mg} \mathrm{CaCO}_{3} \mathrm{~L}^{-1}$ \\
\hline Specific conductance & 726 to $817 \mu \mathrm{g} \mathrm{S} \mathrm{cm}-1$ \\
\hline Supplemental aeration & Initiated not later than dpf 36 \\
\hline \multicolumn{2}{|l|}{ Animal husbandry } \\
\hline Animal supply & Xenopus, Dexter, MI, USA \\
\hline Shipped from Supplier & Day 3 post fertilization (dpf) \\
\hline Acclimation & dpf $4-7$ \\
\hline Treatment period & dpf $8-82$ \\
\hline Feed: Sera Micron & $\begin{array}{l}\text { Sera Micron (contaminants and estrogenic potential evaluated) } \\
\text { Contents: } 50 \% \text { protein, } 8 \% \text { fat; } 4 \% \text { fibre; } 11 \% \text { ash. }\end{array}$ \\
\hline Feeding rate-acclimation & $\begin{array}{l}\text { dpf } 4-5 \text {; per } 300 \text { larvae: } 200 \mathrm{mg} \text {; if free swimming, dpf } 6-8 \text { : } \\
200 \mathrm{mg} \text { twice daily (based on the intake of food by the larvae) }\end{array}$ \\
\hline Feeding rate- $-\mathrm{NF}$ stages $46-66$ & $\begin{array}{l}77 \mathrm{mg} \mathrm{L}^{-1} \text { : fed three times daily, } 300 \mathrm{mg} / \operatorname{tank} \text { from dpf } 8 \text {, } \\
\text { increasing to } 900 \mathrm{mg} / \mathrm{tank} \text { at dpf } 33 \text {, then adjusted during } \\
\text { experiment as animals were removed (dead, froglets) }\end{array}$ \\
\hline Exposure chamber cleaning & Daily \\
\hline Exposure chamber replacement & As needed \\
\hline Water-quality parameters & $\begin{array}{l}\text { Hardness, ammonia, nitrate, } \mathrm{pH} \text {, specific conductivity twice a } \\
\text { week; DO three times a week }\end{array}$ \\
\hline Temperature & $22 \pm 1^{\circ} \mathrm{C}$ (verified twice daily, measured once a week) \\
\hline Light intensity & $100-500$ lux (measured once weekly, at level of surface of water) \\
\hline Light:dark cycle & $12: 12 ; 30$-min transition ( $30 \%$ of full light) \\
\hline \multicolumn{2}{|l|}{ Experimental design } \\
\hline $\begin{array}{l}\text { Performed in compliance with Good } \\
\text { Laboratory Practice Standard }\end{array}$ & Yes \\
\hline Colour coded (blind) treatment & Yes \\
\hline Randomization of tadpoles & $\begin{array}{l}\text { Tadpoles distributed in rotation one or two at a time to transport } \\
\text { vessels to contain } 25 \text {, then vessels were randomly assigned to } \\
\text { test tanks }\end{array}$ \\
\hline Randomization of tank clusters & $\begin{array}{l}\text { Completely randomized placement; one cluster consists } \\
\text { of four tanks }\end{array}$ \\
\hline Negative control & Water (eight replicates, two clusters) \\
\hline Treatment $17 \beta$-estradiol concentrations & $\begin{array}{l}0.015,0.2,1.5,6.0 \mu \mathrm{g} \mathrm{E} 2 \mathrm{~L}^{-1} \text {; eight replicates; two clusters } \\
\text { for each group }\end{array}$ \\
\hline Tank volume & $9 \mathrm{~L}$ (water volume $7 \mathrm{~L}$ ), tanks covered \\
\hline Tank flow rate & $50 \mathrm{~L} \mathrm{day}^{-1}$ \\
\hline Number of animals & 200 larvae per treatment group \\
\hline Animal load density & Less than $1 \mathrm{~g} \mathrm{~L}^{-1}$ water; 25 larvae/tank \\
\hline HPLC-MS-MS verification & dpf 8 all tanks; dpf $16-81$ weekly (alternating tanks) \\
\hline
\end{tabular}

\section{In-life assessment of tadpoles}

\section{Appearance and behaviour}

No effects of E2 treatment on tadpoles condition, behaviour, or external appearance was observed in any of the treatment groups at any time throughout the entire course of Experiment 1A or Experiment 1B.
Survival

Excellent survival was achieved in both experiments in controls as well as in E2 treated groups. The total survival was $92 \%$ in Experiment $1 \mathrm{~A}$ and $99 \%$ in Experiment B. In Experiment 1A, survival in the combined negative control, $0.2,1.5$, and $6.0 \mu \mathrm{g} \mathrm{E} 2 \mathrm{~L}^{-1}$ treatment groups was 90.8, 94.5, 95.0, and 88.0\%, respectively. In Experiment 1B survival 


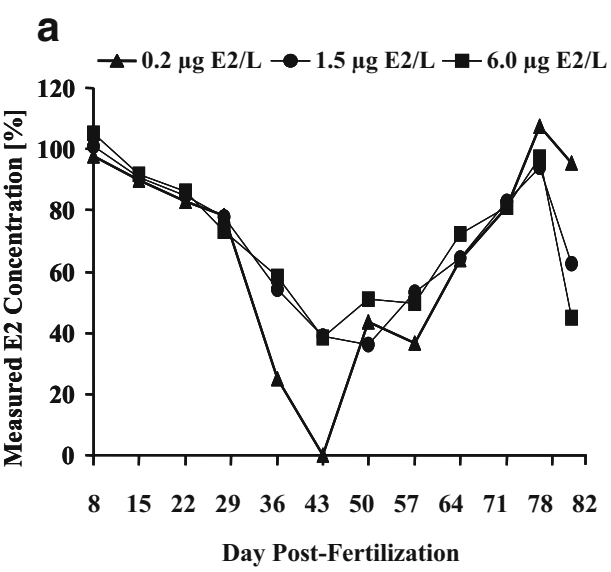

Fig. 1 Comparison of measured mean E2 concentrations in water samples of E2 treatments in the flow-through system. Mean values represent the concentrations of E2 of weekly sampling intervals from dpf 6 or 8 through the last sampling interval on termination of the experiments on dpf 82. a, E2 concentrations of Experiment 1A; b, E2

rates were $100 \%$ in the negative control and $97.5,97.5$, and $99.5 \%$ in the $0.015,0.2$, and $1.5 \mu \mathrm{g} \mathrm{E} 2 \mathrm{~L}^{-1}$ exposure groups, respectively.

Snout-to-vent length and weight

In Experiment 1A, for females the average length values were, $22.2 \pm 0.1,22.1 \pm 0.1$, and $22.8 \pm 0.1 \mathrm{~mm}$ in the 0.2 , 1.5 , and $6.0 \mu \mathrm{g} \mathrm{E} 2 \mathrm{~L}^{-1}$ treatment group compared with $22.0 \pm$ $0.2 \mathrm{~mm}$ in the combined control group. Males treated with E2 had an average snout-to-vent length of $21.8 \pm 0.1,22.1 \pm$ 0.6 , and $23.0 \pm 0.1 \mathrm{~mm}$ in the combined control, 1.5, and $6.0 \mu \mathrm{g} \mathrm{E} 2 \mathrm{~L}^{-1}$ treatment group, respectively. The increase in the mean weight of males was more pronounced than the increase in the mean weight of females (Fig. 2).

In Experiment 1B no statistically significant differences between the snout-to-vent length for females and males were observed. The snout-to-vent length for females and males in

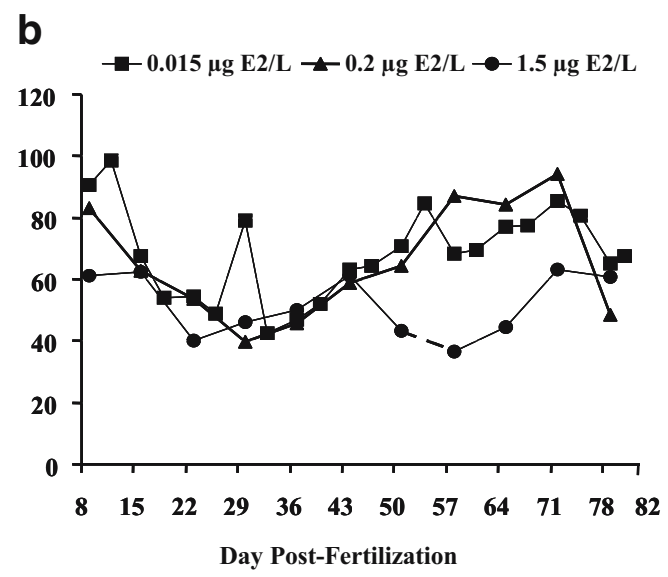

concentrations of Experiment 1B. The limit of quantification was $0.00500 \mu \mathrm{g} \mathrm{E} 2 \mathrm{~L}^{-1}$, calculated as the product of the concentration of the lowest calibration standard $\left(0.100 \mu \mathrm{g} \mathrm{E} 2 \mathrm{~L}^{-1}\right)$ and the dilution factor of the matrix blank samples $\left(0.0500 \mu \mathrm{g} \mathrm{E} 2 \mathrm{~L}^{-1}\right)$

the negative control group was $17.2 \pm 1.5$ and $17.0 \pm 1.6 \mathrm{~mm}$, respectively. For females and males treated with $1.5 \mu \mathrm{g}$ E2 $\mathrm{L}^{-1}$ snout-to-vent length was $17.5 \pm 1.5$ and $16.3 \pm$ $1.3 \mathrm{~mm}$, respectively. No statistically significant treatmentrelated effect was observed for body weight either in females or in males. At completion of metamorphosis, frogs from Experiment $1 \mathrm{~A}$ weighed more than twice as much as frogs from Experiment 1B, regardless of the gender (Fig. 2).

Time course of metamorphosis

On average, the process of metamorphosis for tadpoles took longer in Experiment 1A than in Experiment 1B. In Experiment 1A, the age at which the first frog in the experiment completed metamorphosis was delayed by 6 days (dpf 44) in each E2 treatment group compared with animals in Experiment 1B (dpf 38) (Fig. 3). In Experiment $1 \mathrm{~A}$ exposure of females to $0.2,1.5$, and $6.0 \mu \mathrm{g} \mathrm{E} 2 \mathrm{~L}^{-1}$
Fig. 2 Body weight (means \pm $\mathrm{SD}$ ) of $\mathbf{a}$, females, and $\mathbf{b}$, males, after exposure to E2 from dpf 6 or 8 in a flow-through system until completion of metamorphosis or day 82 post-fertilization. $0.015 \mu \mathrm{g} \mathrm{E} 2 \mathrm{~L}^{-1}$ was not used in Experiment $1 \mathrm{~A}$ and $6.0 \mu \mathrm{g} \mathrm{E} 2 \mathrm{~L}^{-1}$ was not used in Experiment 1B. Neg Ctrl, negative control group

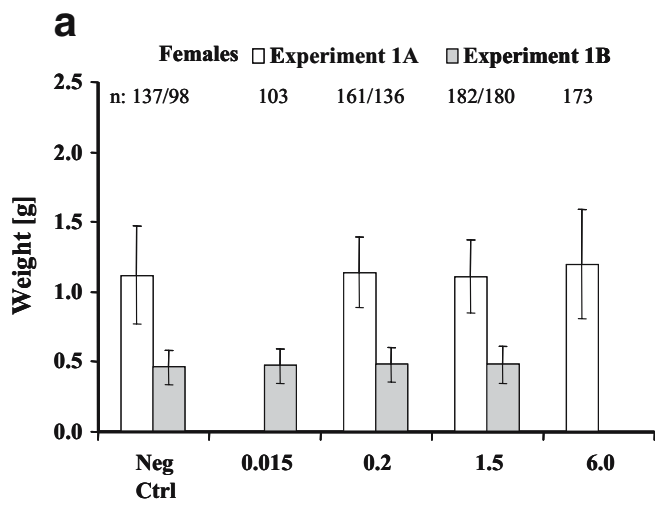

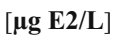

b

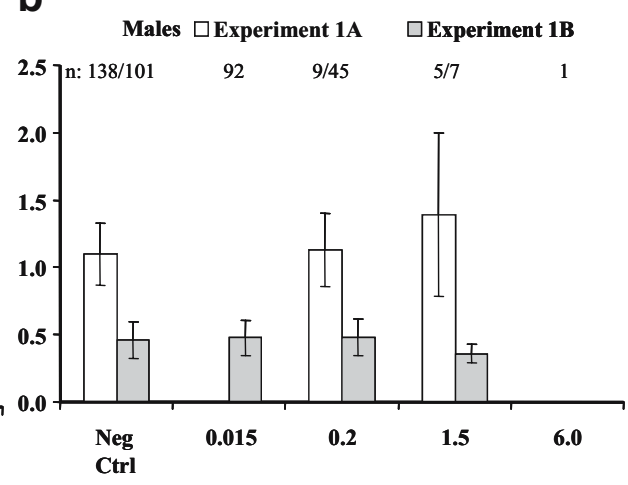

[Mg E2/L] 
Fig. 3 Cumulative portion of $X$. laevis frogs completing metamorphosis after exposure to different concentrations of E2 from day 6 or 8 post-fertilization in a flow-through system until completion of metamorphosis or day 82 post-fertilization. The number of individuals per treatment group $(n)$ is given in the legend. a, portion of females in Experiment $1 \mathrm{~A} ; \mathbf{b}$, portion of females in Experiment 1B; $\mathbf{c}$, portion of males in Experiment 1A (just one male was observed in the $6.0 \mu \mathrm{g} \mathrm{E} 2 \mathrm{~L}^{-1}$ group); d, portion of males in Experiment 1B. Neg $\mathrm{Ctrl}$, negative control group a

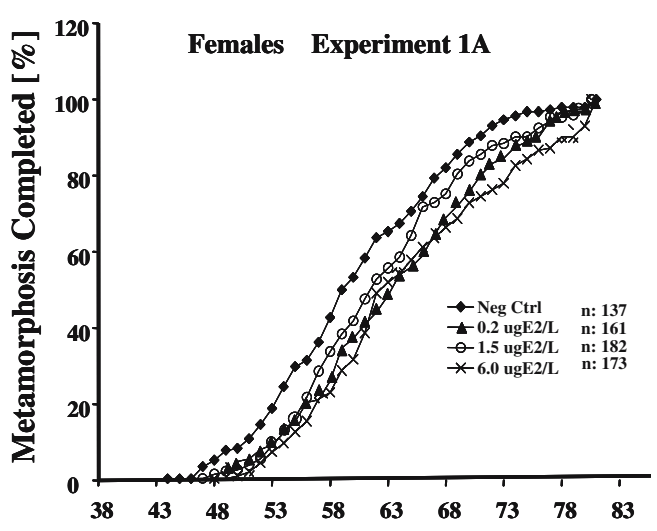

C

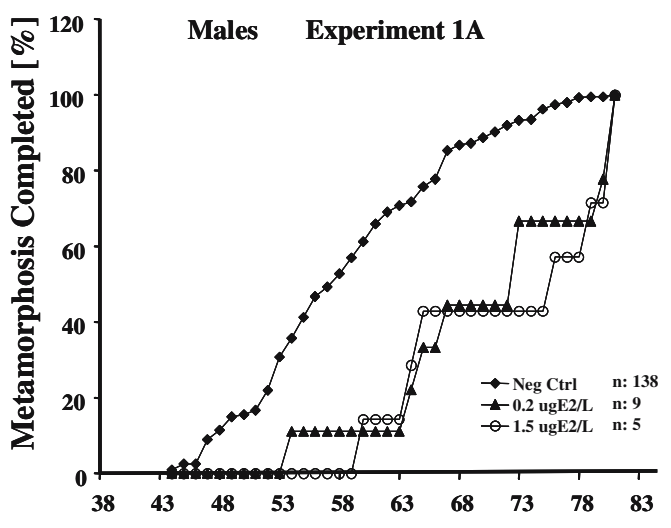

Day Post-Fertilization b

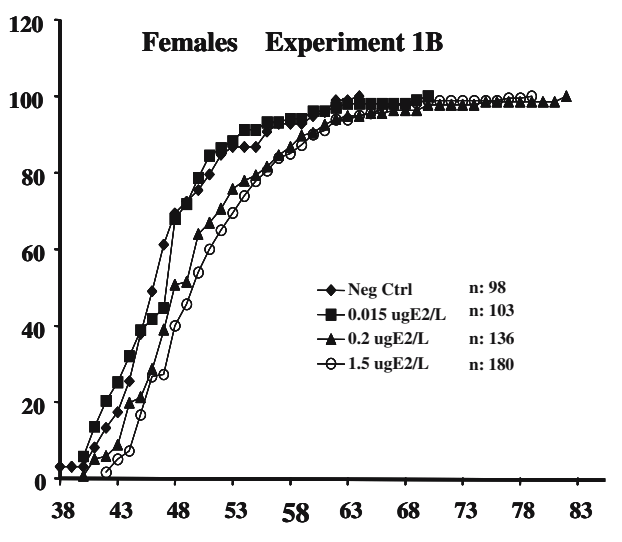

d

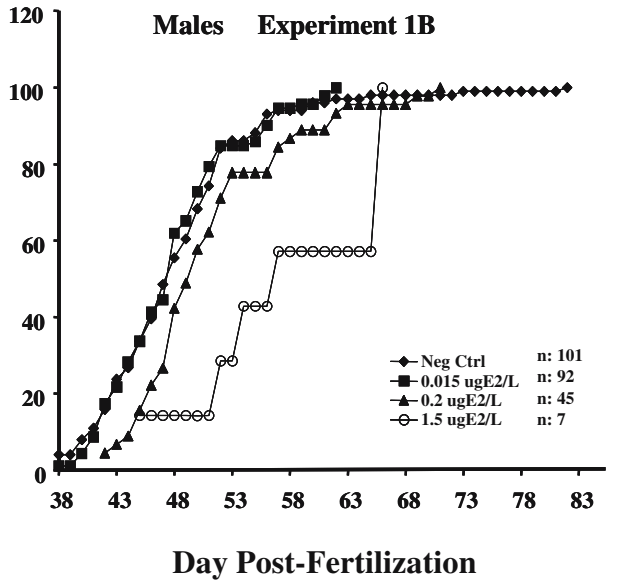

resulted in a slight delay of metamorphosis. In Experiment $1 \mathrm{~B}$, the time course of metamorphosis for females in the $0.015 \mu \mathrm{g} \mathrm{E} 2 \mathrm{~L}^{-1}$ treatment group was similar to that for females in the negative control group but exposure to 0.2 and $1.5 \mu \mathrm{g} \mathrm{E} 2 \mathrm{~L}^{-1}$ caused a delay of completion of metamorphosis (Fig. 3a,b). A comparable picture for the cumulative time course of metamorphosis of males is shown in Fig. 3c,d. In Experiment 1A, males treated with 0.2 and $1.5 \mu \mathrm{g} \mathrm{E} 2 \mathrm{~L}^{-1}$ had a delay in completing metamorphosis of approximately ten days compared with males in the negative control group. In Experiment 1B metamorphosis of male frogs in the $0.2 \mu \mathrm{g}$ E2 $\mathrm{L}^{-1}$ treatment group was slightly postponed whereas for males treated with $1.5 \mu \mathrm{g} \mathrm{E} 2 \mathrm{~L}^{-1}$ completion of metamorphosis was delayed by three days. The lowest E2 concentration used obviously did not affect the mean time to complete metamorphosis.

Exposure to E2 had no effect upon the percentage of surviving tadpoles that completed metamorphosis on $\mathrm{dpf} 82$ (97.4\% in Experiment 1A, 99.1\% in Experiment 1B). By dpf 82,25 (out of 920) and 7 (out of 789) individuals failed to complete metamorphosis in Experiment 1A and Experiment
$1 \mathrm{~B}$, respectively, and no treatment-related effect was observed. In Experiment 1B, 1, 2, and 4 individuals failed to complete metamorphosis by dpf 82 in the negative control, 0.2 , and, $1.5 \mu \mathrm{g} \mathrm{E} 2 \mathrm{~L}^{-1}$ treatment groups, respectively.

Mean age at completion of metamorphosis

The differences in the time course of metamorphosis described in the previous section are reflected in the mean ages of frogs at completion of metamorphosis in each of the treatment groups. In Experiment 1A, the mean ages at completion of metamorphosis of females treated with 0.2 , 1.5, and $6.0 \mu \mathrm{g} \mathrm{E} 2 \mathrm{~L}^{-1}$ were dpf $64.2 \pm 7.6,62.9 \pm 7.9$, and $65.1 \pm 9.2$, respectively, and substantially greater than the mean age in the negative control group (dpf 61.4 \pm 8.2 ) (Fig. 4). In contrast, in Experiment 1B females treated with the different E2 concentrations showed a dose response with a significant increase noted in the $0.2 \mu \mathrm{g} \mathrm{E} 2 \mathrm{~L}^{-1}$ group (dpf 50.7 \pm 7.5$)$ and a greater effect $(\operatorname{dpf} 51.5 \pm 6.6)$ in the $1.5 \mu \mathrm{g} \mathrm{E} 2 \mathrm{~L}^{-1}$ treatment group compared with dpf $47.8 \pm$ 5.6 for females in the negative control group. For males in Experiment 1A, the mean age at completion of metamor- 


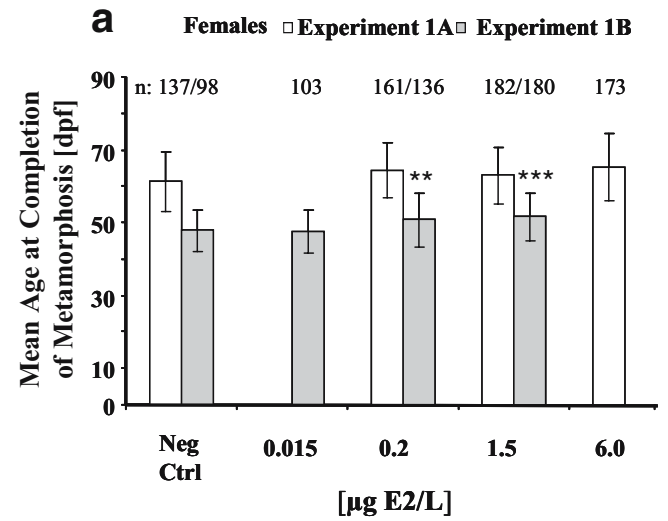

Fig. 4 Mean age at completion of metamorphosis (mean \pm SD) by treatment group for female, $\mathbf{a}$, and male, $\mathbf{b}$, frogs at completion of metamorphosis or on day 82 post-fertilization. $0.015 \mu \mathrm{g} \mathrm{E} 2 \mathrm{~L}^{-1}$ was not used in Experiment $1 \mathrm{~A}$ and $6.0 \mu \mathrm{g} \mathrm{E} 2 \mathrm{~L}^{-1}$ was not used in Experiment 1B. Only one male frog was observed in the $6.0 \mu \mathrm{g}$ E2 L ${ }^{-1}$ group in Experiment $1 \mathrm{~A}$. Neg Ctrl, negative control group. For

phosis was increased from dpf $60.6 \pm 9.4$ in the negative control to dpf $70.9 \pm 9.3$ and dpf $72.3 \pm 9.0$ in the 0.2 and $1.5 \mu \mathrm{g} \mathrm{E} 2 \mathrm{~L}^{-1}$ treatment groups, respectively. In Experiment $1 \mathrm{~B}$, the mean age at completion of metamorphosis of males was statistically significant greater in the $0.2 \mu \mathrm{g}$ E2 $\mathrm{L}^{-1}$ (dpf 51.2 \pm 6.6 ) and $1.5 \mu \mathrm{g} \mathrm{E} 2 \mathrm{~L}^{-1}$ (dpf 58.0 \pm 8.3 ) treatment groups than in the negative control group ( $\mathrm{dpf}$ 48.5 \pm 6.8$)$ (Fig. 4).

\section{Appearance and examination of non-gonadal organs}

No externally visible morphologic abnormalities were observed in each treatment group in either experiment. Likewise, inspection of the liver, stomach, intestine, kidney for tumours, lesions or any other remarkable features had no effect.

Determination of sex, percent female, male, and mixed sex by gross examination

The percentages of male, female, and mixed-sexed animals were calculated based on frogs that completed metamorphosis (NF stage 66) among all animals. In Experiment 1A, the percentage of female phenotype was increased in all E2 treated groups. In the $0.2,1.5$, and $6.0 \mu \mathrm{g} \mathrm{E} 2 \mathrm{~L}^{-1}$ treatment group 88.4, 95.8, and $98.3 \%$ of frogs showed female phenotype. In Experiment 1B, the incidence of female phenotype in the E2 treated groups displayed a statistically significant distinct dose-responsive increase with a high percentage of females observed for the $0.2(70.5 \%)$ and $1.5 \mu \mathrm{g} \mathrm{E} 2 \mathrm{~L}^{-1}(92.3 \%)$ treatment groups, respectively (Fig. 5). The E2 concentration that results in an increase of female phenotype to $75 \%$ is defined as the effective concentration $\left(\mathrm{EC}_{50}\right)$. Based on the feminization effect

\section{b Males $\square$ Experiment 1A $\square$ Experiment 1B}

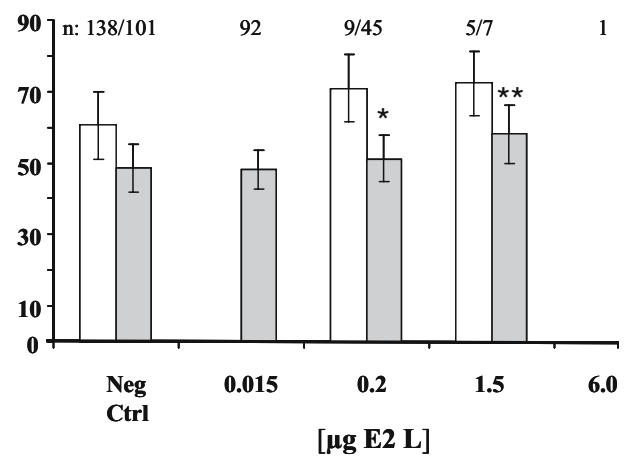

Experiment 1B significant differences are marked by asterisks $\left({ }^{*} p<\right.$ $0.05,{ }^{*} p<0.01,{ }^{* * *} p<0.001$; two-sided Wilcoxon-Mann-Whitney test of equality with negative control group). A Kruskal-Wallis test of overall group differences was significant (females $p<0.0001$, males $p=0.0009$ ) and a Jonckheere-Terpstra test of trend was significant (females $p<0.0001$, males $p=0.0062$ )

observed in Experiment $1 \mathrm{~B}$ the $\mathrm{EC}_{50}$ was calculated to be $0.12 \mu \mathrm{g} \mathrm{E} 2$.

In Experiment $1 \mathrm{~A}$, the percentage of mixed sex individuals were $6.9 \%(13 / 189), 2.1 \%(4 / 191)$ and $1.1 \%$ $(2 / 176)$ in the $0.2,1.5$, and $6.0 \mu \mathrm{g} \mathrm{E} 2 \mathrm{~L}^{-1}$ treatment groups, respectively. In Experiment 1B, the incidences of mixedsex animals were statistically significant with $6.2 \%(12 /$ $193)$ and $4.1 \%(8 / 195)$ in the 0.2 and $1.5 \mu \mathrm{g} \mathrm{E} 2 \mathrm{~L}^{-1}$ treatment groups, respectively (Fig. 5). In both experiments the percentage of frogs displaying mixed sex gonads was higher in E2-treated groups than in the negative control groups. When results from the two experiments are compared, the percentage of mixed sex animals was seen to be similar in equal E2 concentrations.

Segmental aplasia was detected in Experiment 1A in one of nine male individuals out of the $0.2 \mu \mathrm{g} \mathrm{E} 2 \mathrm{~L}^{-1}$ treatment group. In Experiment 1B, segmental aplasia was observed in four of $101(4.0 \%)$, nine of $92(9.8 \%)$, eighteen of 45 $(40.0 \%)$ and four of seven $(57.1 \%)$ male frogs in the 0.015 , 0.2 , and $1.5 \mu \mathrm{g} \mathrm{L}^{-1}$ treatment groups, respectively. Thus, the frequency of segmental aplasia in the 0.2 and $1.5 \mu \mathrm{g}$ E2 $\mathrm{L}^{-1}$ groups was significantly elevated. Pearling was observed in two of nine and one of five male frogs the 0.2 , and $1.5 \mu \mathrm{g}$ E2 $\mathrm{L}^{-1}$ groups, respectively, in Experiment 1A. In Experiment $1 \mathrm{~B}$, the occurrence of pearling was determined in two frogs out of 45 within the $0.2 \mu \mathrm{g} \mathrm{E} 2 \mathrm{~L}^{-1}$ treatment group. Intersex was not found in any of the 1593 Xenopus evaluated for gonad morphology in both studies. Figure $6 a, b$ demonstrate ordinary developed ovarian and testes tissue that was assumed to be "normal gonad morphology" for gross morphological evaluation. Figure $6 \mathrm{c}$ to e illustrate gonads showing mixed sex, pearling, and segmental aplasia and clarify the terminology which was applied in these experi- 
Experiment 1A

Experiment 1B

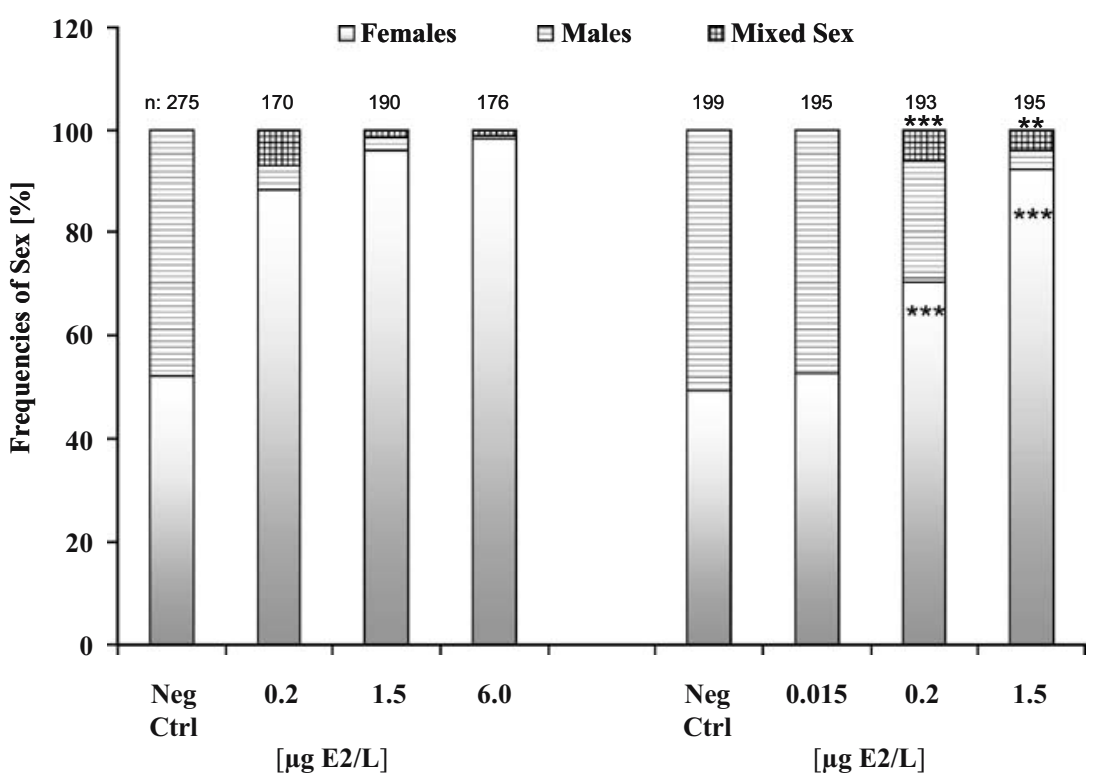

Fig. 5 Individual bars represent frequencies of sex of $X$. laevis frogs among all animals according to treatment group based on gross morphological evaluation; the total number of frogs $(n)$ that completed metamorphosis, is given on top of the bars. Tadpoles were exposed to E2, in a flow-through system, from day 6 or 8 post-fertilization through completion of metamorphosis or day 82 post-fertilization. The $\mathrm{EC}_{50}$ was calculated from the results of Experiment $1 \mathrm{~B}$ and was $0.12 \mu \mathrm{g} \mathrm{E} 2$. The numbers of frogs in the negative control in Experiment 1A was higher for evaluation of gender because the

ments to describe morphological changes in gonadal appearance of $X$. laevis due to E2 treatment. To allow the variability of the morphological appearance of gonads to be described, an extensive terminology to include the biological variability was developed and used in the two experiments (Table 1). In Experiment 1A there were apparent differences in the occurrence of ovaries that were truncated, narrow entire margin, or had enlarged masses. However, no differences in morphological characteristics were observed between E2-treated and control frogs in Experiment 1B.

\section{Gonadal measurement}

Because of the subjective nature of gross gonad morphological assessment, quantitative measurements of gonad area were performed on digital images.

In Experiment 1A, mean gonad areas of female and male frogs were approximately twice as large as in animals of the corresponding gender in Experiment 1B. The mean gonad

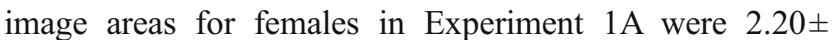
$0.82 \mathrm{~mm}^{2}, 2.21 \pm 0.89 \mathrm{~mm}^{2}, 2.09 \pm 0.92 \mathrm{~mm}^{2}$, and $2.23 \pm$ $0.92 \mathrm{~mm}^{2}$ in the combined negative control, $0.2,1.5$, and $6.0 \mu \mathrm{g} \mathrm{E} 2 \mathrm{~L}^{-1}$ treatment groups, respectively. In Experiment $1 \mathrm{~B}$, for females treated with $0.015,0.2$, and $1.5 \mu \mathrm{g} \mathrm{E} 2$ $\mathrm{L}^{-1}$ mean gonad image areas were $1.21 \pm 0.41 \mathrm{~mm}^{2}, 1.27 \pm$ animals which were excluded from calculation of weight and length were included in calculation of the portion of males, females, and mixed sex. Neg Ctrl, negative control group. For Experiment 1B asterisks denote significant differences $(* * p<0.01, * * * p<0.001$; two-sided Fisher's exact test for comparison to negative control). Both an overall exact chi-square test of equality of all experimental groups and a Cochran-Armitage trend test were statistically significant $(p<$ 0.05 ) in every case

$0.44 \mathrm{~mm}^{2}$, and $1.32 \pm 0.41 \mathrm{~mm}^{2}$, respectively, compared with $1.23 \pm 0.42 \mathrm{~mm}^{2}$ in the negative control group. Mean gonad areas in females treated with $1.5 \mu \mathrm{g} \mathrm{E} 2 \mathrm{~L}^{-1}$ were significantly increased $(p<0.05)$. In Experiment $1 \mathrm{~A}$, the measured mean gonad areas of males in the combined control, 0.2 and $1.5 \mathrm{E} 2 \mathrm{~L}^{-1}$ were $1.28 \pm 0.2 \mathrm{~mm}^{2}, 1.39 \pm$ $0.2 \mathrm{~mm}^{2}$, and $1.70 \pm 0.3 \mathrm{~mm}^{2}$, respectively. In Experiment $1 \mathrm{~B}$, males treated with $0.015,0.2$, and $1.5 \mu \mathrm{g} \mathrm{E} 2 \mathrm{~L}^{-1}$ had a slight increase of mean gonad areas $0.82 \pm 0.20 \mathrm{~mm}^{2}, 0.85 \pm$ $0.19 \mathrm{~mm}^{2}$, and $0.89 \pm 0.14 \mathrm{~mm}^{2}$, respectively, compared with the negative control $\left(0.77 \pm 0.22 \mathrm{~mm}^{2}\right)$. A KruskalWallis test of overall group differences was marginally nonsignificant $(p=0.079)$ but a Jonckheere-Terpstra test of trend was significant $(p=0.0092)$.

\section{Discussion}

Gonadal development in anuran amphibians has been proposed as a valuable model to evaluate the physiological consequences of exposure to EAC with (anti)estrogenic and/or (anti)androgenic activity [30]. It has long been known that treatment of tadpoles with gonadal steroids can disrupt normal gonadal development in several anuran species and might even lead to complete sex reversal [31, 

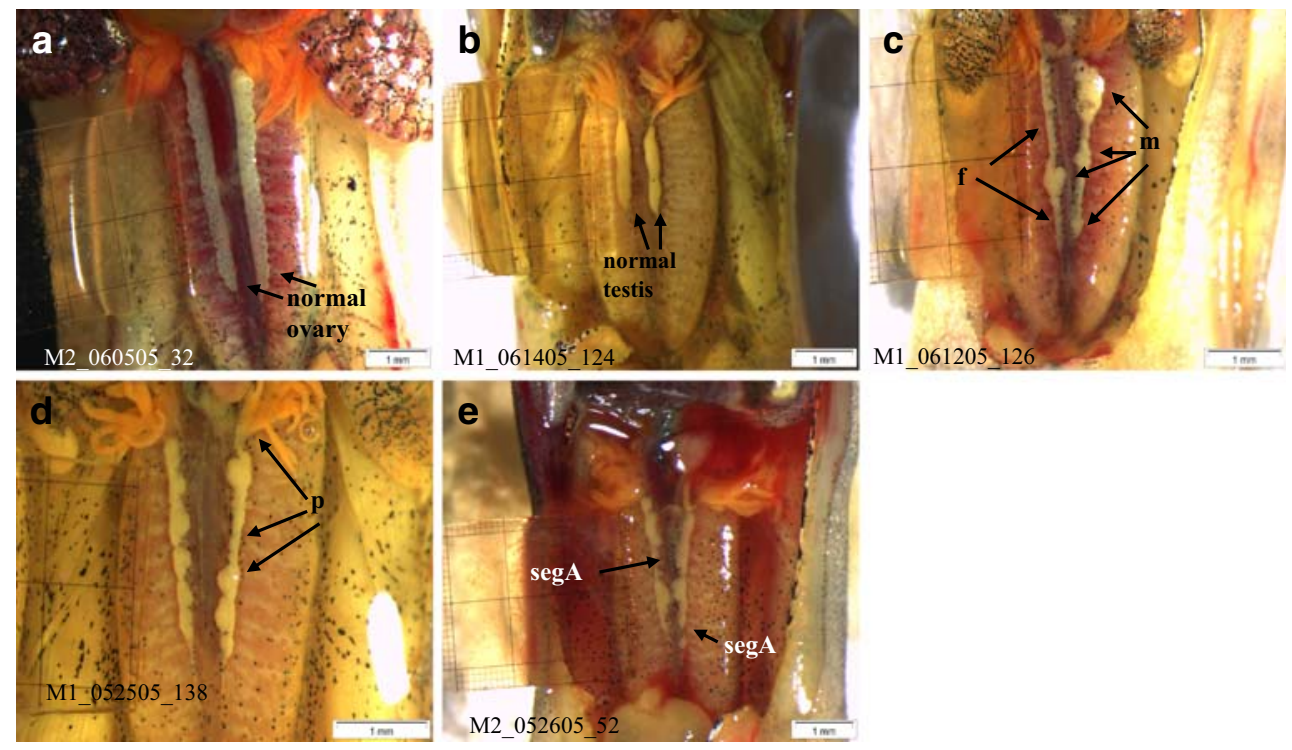

Fig. 6 a. Ovary of $X$. laevis revealing segmented, lobular structure and clearly visible internal melanocytes in the tissue; the length of the ovary is slightly shorter than the length of the kidney. b. In contrast, a testis is shorter relative to the length of the kidney (half of the kidney), straight shaped, and does not contain internal melanocytes. In general testis tissue appears much denser than ovary tissue. c. Mixed sex gonads were defined as the co-occurrence of both ovarian and testicular tissue in a single gonad. The ovary tissue in the presented gonad shows a reduced lobular structure, just a few melanophores,

32]. However, studies on the potential effects of EAC on anuran gonadal development have produced variable and, in some cases, inconsistent results. From analysis of published studies it appears that some of the variability between EAC studies may be because of differences between the experimental conditions employed. One example to illustrate this situation is the outcome of three different exposure studies assessing the effects of bisphenol A (BPA) on gonadal development in X. laevis [15-17]. By using a semi-static exposure system, feminization of tadpoles due to BPA treatment was reported by Kloas [15] and Levy [17]. Attempts to replicate these findings in a flow-through exposure system by Pickford [16] were not successful. A more recent example includes inconsistent results observed in different studies on the putative effects of atrazine on survival, growth, metamorphosis, and sexual development of $X$. laevis [20, 21, 23]. The failure to reproduce the original findings leaves regulatory authorities with many uncertainties and in consequence, may prevent sound assessment of potential risks associated with the use of the chemicals of concern.

Contradictory results from several studies of atrazine, and the criticism associated with each of these studies, made it impossible for the US EPA to perform an unambiguous evaluation of the actual impact of atrazine on development and sexual differentiation in X. laevis. The whereas the testis tissue appears bulbous. Arrows indicate the different gonad structures, $f$, ovary-like tissue, and $m$, male like tissue. d. Pearling $(p)$ was characterized by the presence of multiple, prominent segmental enlargements and/or attenuations along the length of one or both gonads. e. Segmental aplasia $(\operatorname{seg} A)$ was classified as nodular islands of testicular or ovarian tissue, with either intervening membranous connections or no connections. The kidney and the attached gonad tissue were fixed with Bouin's solution

US EPA therefore requested further independent studies to be conducted using a standardized test protocol including validated positive control treatments and an optimized study design [33]. To address uncertainties resulting from inconsistencies of previously reported data, the current multi-site study was undertaken in order to develop and refine an optimized testing protocol for the use in developmental studies with $X$. laevis tadpoles. The current paper presents the results of the two independent exposure experiments that were performed by two different laboratories. A first experiment (Experiment 1A) served as a pilot study to identify appropriate testing conditions for the development of a standardized testing protocol. Accordingly, the test protocol used in the follow-up experiment (Experiment 1B) included some modifications reflecting the experience gained in Experiment 1A. In combination, the current multi-site study aimed at a characterization of the general performance of the tadpoles using the optimized testing protocol and a detailed evaluation of concentrationdependent effects of E2 on tadpole growth, larval development and sexual differentiation.

The testing protocol under investigation specified the use of a flow-through exposure system to achieve E2 exposure of tadpoles. The main advantages of flow-through systems versus static renewal systems are the maintenance of constant testing conditions (e.g., water quality) and the 
continuous delivery of the test substance to the exposure vessels to achieve stable exposure of the test species to the test substance. In the two exposure experiments with E2, however, difficulties were encountered with regard to the maintenance of the target test concentration of E2 even under flow-through conditions. Although E2 concentrations in the stock solutions were within acceptable ranges in both exposure studies, and the quantity of E2 metered into the tanks was correct, actual E2 concentrations in the exposure tanks decreased to levels well below nominal test concentrations during the entire course of the experiments (Fig. 1). These observations clearly indicate that in future studies care must be taken to maintain constant nominal concentrations of the test compound throughout exposure. It is recommended the flow rate of the stock solutions be adjusted on a daily basis according to the actual test substance concentration present in the tanks.

Comparison of the time-course of E2 concentration changes with estimates of the biomass present in E2 treatment tanks at different times during Experiments 1A and $1 \mathrm{~B}$ suggests that $\mathrm{E} 2$ concentrations were inversely related to changes in total biomass. Aqueous E2 concentrations decreased concurrent with the increase in body size and body weight of tadpoles during premetamorphosis (NF stages up to 52), prometamorphosis (NF stages 53 to 57 ), and climax (58 to 66). Concentrations of E2 began to increase as tadpoles that completed metamorphosis were removed from the test tanks, and as remaining tadpoles began to lose weight during tail resorption. Figure 7 illustrates that E2 concentrations were inversely related to changes in total biomass of the tadpoles. Furthermore, it should be noted that the biomass was greater in Experiment $1 \mathrm{~A}$ than in Experiment $1 \mathrm{~B}$ and the decline in aqueous E2 concentration was more marked in Experiment 1A. These observations, combined with the relatively high octanolwater partition coefficient of $\mathrm{E} 2\left(\log K_{\mathrm{ow}} 3.94\right)$ suggest that additional measures (e.g., gradual increase of amounts of E2 delivered to the test tanks) are required to maintain a constant exposure to E2 in terms of actual aqueous E2 concentrations. In semi-static systems E2 disappears quick- ly, which suggests the animal may absorb the E2. Only few studies are available that have addressed this aspect. Results from Hayes and Licht [34] suggest that exogenous E2 is readily metabolized by $X$. laevis and other anuran species, and there was no evidence of bioaccumulation of E2 in anuran tadpoles. However, metabolic enzymes and the sites of E2 metabolism in anuran tadpoles are largely unknown. Possible candidate metabolites might include various E2 conjugates, but neither the test solutions nor the test animals have been examined analytically for the presence of such metabolites. To the best of our knowledge, there are also no data available regarding possible developmental profiles of E2-metabolising capacities that might explain the transient reduction of aqueous E2 concentrations in the present studies. It is, further, not known whether any of the putative metabolites still possess estrogenic or other hormonal activity. Finally, it is possible that factors other than changes in tadpole biomass may have contributed to the observed changes of E2 concentrations. For example, a small fraction of E2 may have been absorbed either in the biofilm or directly on the surface of the glass tanks. Another possibility could be that E2 partition from water to fat in the administered Sera Micron feed ( $\sim 8 \%$ fat) occurred. Notably, daily food amounts administered to each tank were adjusted to total larvae biomass. Therefore, it is an interesting possibility that at least a portion of the E2 dose may reach biological targets in the larvae as a result of oral ingestion of the feed.

An important objective underlying the development of a standardized testing protocol for exposure of $X$. laevis tadpoles was to maintain appropriate water quality throughout the exposure experiments. Thus special care was taken to standardize and refine water quality parameters to ensure optimal growth and development of $X$. laevis tadpoles. Except for a transient decline of DO concentration below desirable levels, all water-quality parameters were within acceptable limits. The decrease of DO concentrations through dpf 43 in Experiment $1 \mathrm{~A}$ and inability to maintain the DO concentration above $60 \%$, may have been due to insufficient cleaning. Based on this observation, the cleaning
Fig. 7 Correlation of changes in E2 concentration and the biomass of growing tadpoles during the exposure period in Experiments $1 \mathrm{~A}$ and $1 \mathrm{~B}$
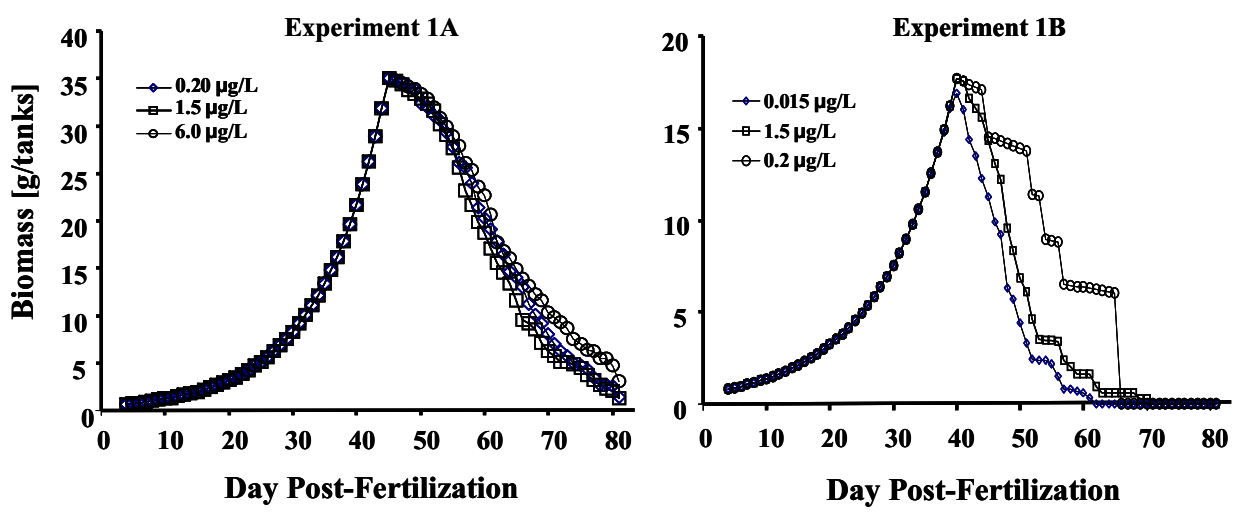
procedure was enhanced, and additional aeration was provided by gently bubbling air through glass pipettes in each tank.

An interesting finding in these two experiments was the effects on growth and development of $X$. laevis tadpoles that occurred due to slight differences in rearing procedures between Experiment 1A and Experiment 1B. Tadpoles in Experiment $1 \mathrm{~A}$ required more time to complete metamorphosis and the metamorphic froglets (NF stage 66) were larger and heavier than those in Experiment 1B. Whereas the relationship between age and size is in accordance with established amphibian life-history models [25], the factors that are responsible for the inter-laboratory differences are not entirely clear in this case. In Experiment 1A, the photoperiod was 16 hours light: 8 hours dark compared with 12 hours light:12 hours dark in Experiment 1B. The mean temperature was approximately $1{ }^{\circ} \mathrm{C}$ lower and more variable $\left( \pm 1^{\circ} \mathrm{C}\right)$ in Experiment 1A. The differences in photoperiod and water temperature are certainly prime candidates to explain the slightly slower development in Experiment 1A. On average, tadpoles in Experiment 1A consumed food 13 days longer than those in Experiment 1B. Subsequently, the longer food consumption of tadpoles in Experiment $1 \mathrm{~A}$ led to greater weight compared with that of the froglets in Experiment 1B. Based on the results achieved in experiments $1 \mathrm{~A}$ and $1 \mathrm{~B}$, and to consider the reported differences on growth and development of $X$. laevis in the literature, it is obviously important to standardize the test systems.

Results from Experiment 1B indicated that most of the tadpoles (92\%) from the negative control group completed metamorphosis within a relatively short time (18 days), whereas metamorphosis was delayed (26 days) in a few tadpoles only $(7.5 \% ; 15 / 199)$. In contrast, time to metamorphosis in Experiment 1A, was much more variable, because $78.5 \%(216 / 275)$ of the tadpoles completed metamorphosis within twenty-two days and 21.5\% (59/275) in thirteen days. Furthermore, tadpoles in Experiment 1A completed metamorphosis later than in Experiment 1B (Fig. 8). Thus, the use of the improved testing protocol in Experiment 1B was associated with a reduction in the time needed for completion of metamorphosis, which resulted in much more homogenous development of the test organisms. The latter finding is particularly important given the fact that still only few data are available upon which one could build a set of performance criteria to assess the validity of exposure experiments with $X$. laevis tadpoles. Homogenous growth and development in the negative control group is certainly one important aspect that deserves special attention. Generally, it can be proposed that homogenous rates of tadpole growth and development will reflect appropriate culture and testing conditions. Furthermore, any reduction in the inter-individual variability of growth and development will enable more sensitive assessment of the possible

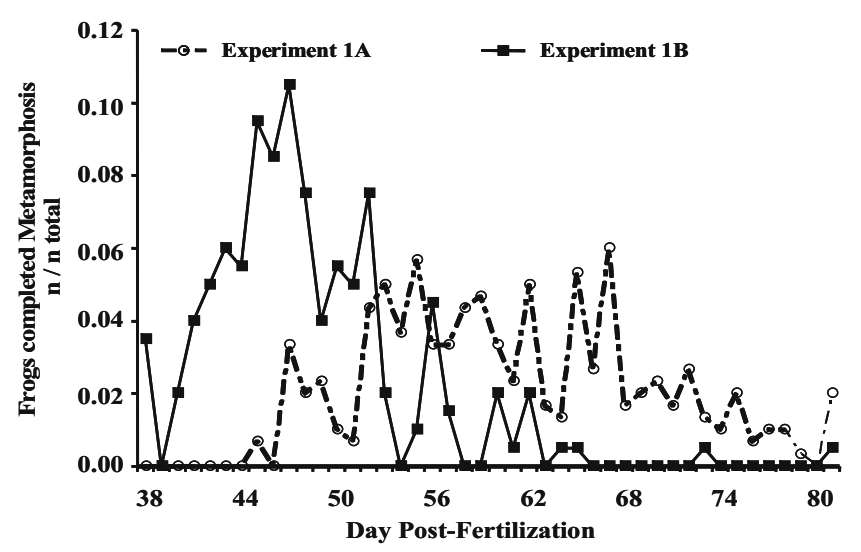

Fig. 8 Proportion of male and females frogs $(n)$ of the negative control groups completing metamorphosis during the course of the studies, based on the total number of animals surviving in Experiments $1 \mathrm{~A}$ and $1 \mathrm{~B}$

effects of a test compound on the development of tadpoles. To this end, the robust demonstration of altered rates of development due to test compound exposure will also provide additional information for interpretation of the effects of the test compound on gonadal development (e.g., identification of systemic toxicity).

In contrast, it is still difficult to assess the validity of an exposure experiment based on the time required for completion of metamorphosis. According to Nieuwkoop and Faber [25] the average time to reach stage 66 is dpf 58. In Experiment 1B, the average time to stage 66 was still shorter, being dpf $47.8 \pm 5.6$ and $48.5 \pm 6.8$ for female and male frogs, respectively. This reduction of the time needed for tadpoles to complete metamorphosis is likely a result of the various efforts to optimize an array of biotic and abiotic factors known to affect tadpole growth and development.

An important element of experimental approaches used to assess the estrogenic activity of chemicals is the choice of an appropriate positive control treatment to confirm the validity of the experimental system. Therefore, a major focus of the current multi-site study was to establish a concentrationresponse relationship for E2 treatment on sexual differentiation of $X$. laevis. The results from Experiment $1 \mathrm{~A}$ were not appropriate to demonstrate this relationship because all E2 concentrations $\left(0.2,1.5\right.$, and $6.0 \mu \mathrm{g}$ E2 $\left.\mathrm{L}^{-1}\right)$ employed in Experiment $1 \mathrm{~A}$ caused a very high percentage of phenotypic females. Based on these observations, the E2 test concentrations were modified in Experiment $1 \mathrm{~B}$, and the use of E2 concentrations of 0.015, 0.2 and $1.5 \mu \mathrm{g}$ E2 $\mathrm{L}^{-1}$ revealed a clear concentration-dependent increase in the number of phenotypic females. The data from Experiment 1B allowed the calculation of an $\mathrm{EC}_{50}$ of $0.12 \mu \mathrm{g}$ E2 $\mathrm{L}^{-1}$ resulting in $75 \%$ gonadal female phenotype.

Literature information about E2 concentration-dependent effects on growth, development, and sexual differentiation in X. laevis is rare. In most studies single E2 concentrations 
ranging from 0.3 to $100 \mu \mathrm{g} \mathrm{L}^{-1}$ were used to study effects on gonadal development $[15-17,22,31,35,36]$ and resulted in percentage of female phenotype between 60 , and $100 \%$. Hu et al. [14] applied 1, 10, and $100 \mu \mathrm{g}$ E2 $\mathrm{L}^{-1}$ and reported an increase of female phenotype to 66,99 , and $100 \%$, respectively. Rearing X. laevis larvae under optimized conditions in Experiment $1 \mathrm{~B}$ demonstrated a distinctive sensitivity for gonadal differentiation. This is demonstrated by a clear concentration-responsive effect, and a distinct effective concentration of $0.2 \mu \mathrm{g} \mathrm{E} 2 \mathrm{~L}^{-1}$, as shown by the frequency of female/male individuals and the occurrence of substantial mixed sex and other abnormalities. Comparing the results of Experiments $1 \mathrm{~A}$ and $1 \mathrm{~B}$ regarding gonadal effects of 0.2 and $1.5 \mu \mathrm{g} \mathrm{E} 2 \mathrm{~L}^{-1}$, a similar effect was observed, indicating high reproducibility of the testing protocol. Based on the endogenous E2 concentrations measured in adult $X$. laevis being approximately $28 \mathrm{ng} \mathrm{mL}^{-1}$ for females and $3 \mathrm{ng} \mathrm{mL}^{-1}$ for males, [37] and in froglets approximately $0.002 \mu \mathrm{g}$ E2/fresh body weight [38] the calculated $\mathrm{EC}_{50}$ appears to represent a physiological E2 concentration in X. laevis.

Another question of high interest is how estrogenic EAC might impact gonad gross morphology. While determination of phenotypic sex was a core endpoint in the assessment of the effects of E2 on sexual differentiation, a number of other gross abnormalities were also evaluated. To that end, a glossary of gonadal gross morphological terminology and criteria was included in the study protocol (Table 1). The importance of this glossary cannot be understated, as a substantial degree of diagnostic variability, within and among studies, can be attributed to differences in terminology [39]. For example the word intersex is characterized differently by several authors and is often used interchangeably with the term mixed sex, whereas in the glossary, these terms have different meanings. Therefore, it is difficult to describe morphological changes triggered by EAC in a way that is clear and generally accepted. Furthermore, assessments of gonadal morphology involve subjective judgement, which make studies difficult to interpret and compare. In the current multi-site study the uncertainty arising from the subjective judgement that was necessarily involved in evaluation of the gross morphological assessment each gonad was reduced by having each finding verified by a second biologist. Additionally, digital photographs of each gonad were taken to allow later verification of assessments, and to allow measurement of gonadal image area using image-processing software. Measurement of gonad image area enables objective verification of some of the subjective size-related observations made during the gross assessments. Trend analysis revealed for both sexes in Experiment 1B an increase of mean gonadal area that coincides with an increased age at completion of metamorphosis.
In both experiments, gross morphological evaluation of the gonads revealed the presence of mixed sex, segmental aplasia, and pearling at $0.2 \mu \mathrm{g} \mathrm{E} 2 \mathrm{~L}^{-1}$. It is noteworthy that intersex, characterized as ovarian and testicular tissue in the same individual as separate gonads (left/right), was not found in any of the 1593 frogs evaluated in these two experiments. Interestingly, in both experiments the highest incidence of these testicular abnormalities was observed in tadpoles exposed to $0.2 \mu \mathrm{g}$ E2 $\mathrm{L}^{-1}$. This was most likely due to the greater degree of complete sex reversal at the two higher E2 concentrations, as suggested by the significantly increased proportion of phenotypic females compared with phenotypic males in the 1.5 and $6.0 \mu \mathrm{g} \mathrm{E} 2 \mathrm{~L}^{-1}$ treatment groups. Based on gross morphological evaluation no differences for the terms of main-categories such as hyperor hypoplasia were observed compared with individuals in the negative control in Experiment 1B.

In conclusion, this multi-site study has developed and established an optimized study design and a standardized test protocol to determine optimal growth and development of $X$. laevis larvae. High survival rates, homogenous rates of development, relatively short times to completion of metamorphosis of control animals, and concentrationdependent effects of E2 treatment on gonadal development were achieved using appropriate testing conditions. Based upon these results, it is concluded that the protocol provides a basis for evaluation on potential effects of chronic EAC exposure on gonadal development in $X$. laevis using a flowthrough system. Furthermore, it is our opinion that the protocol could also be successfully applied to investigate the effects of other types of EAC, such as (anti)thyroidal chemicals, on the development of $X$. laevis.

Acknowledgement The authors gratefully acknowledge fruitful cooperation between members of Wildlife International, Ltd, IGB, EPL, Sielken and Associates, and Syngenta for providing critical and stimulating discussions. We appreciate the exceptional encouragement and assistance of all the laboratories' members involved. We also wish to thank the members of the Office of Prevention, Pesticides, and Toxic Substances from the US EPA for constructive criticism and helpful advice.

This work was funded by Syngenta Crop Protection, Inc. The authors declare that there is no conflict of interest that would prejudice the impartiality of this scientific work.

Open Access This article is distributed under the terms of the Creative Commons Attribution Noncommercial License which permits any noncommercial use, distribution, and reproduction in any medium, provided the original author(s) and source are credited.

\section{References}

1. Jobling S, Nolan M, Tyler CR, Brighty G, Sumpter JP (1998) Environ Sci Technol 32:2498-2506

2. Madsen SS, Skovbolling S, Nielsen C, Korsgaard B (2004) Aquat Toxicol 68:109-120 
3. Houlahan JE, Findlay CS, Schmidt BR, Meyer AH, Kuzmin SL (2000) Nature 404:752-755

4. Kiesecker JM, Blaustein AR, Belden LK (2001) Nature 410:681684

5. Jenssen BM (2006) Environ Health Perspect 114(Suppl 1):76-80

6. Orlando EF, Guillette LJ (2007) Environ Res 104:163-173

7. Katsu Y, Lange A, Urushitani H, Ichikawa R, Paull GC, Cahill LL, Jobling S, Tyler CR, Iguchi T (2007) Environ Sci Technol 41:3368-3374

8. Lerner DT, Bjornsson BT, McCormick SD (2007) Environ Toxicol Chem 26:1433-1440

9. ASTM (2004) Standard Guide for Conducting the Frog Embryo Teratogenesis Assay-Xenopus (FETAX), E1439-98, Philadelphia, USA

10. Kikuyama S, Kawamura K, Tanaka S, Yamamoto K (1993) Int Rev Cytol 145:105-148

11. Shi YB (2000) Amphibian Metamorphosis. Wiley-Liss, New York

12. Opitz R, Hartmann S, Blank T, Braunbeck T, Lutz I, Kloas W (2006) Toxicol Sci 90:337-348

13. Oka T, Mitsui N, Hinago M, Miyahara M, Fujii T, Tooi O, Santo N, Urushitani H, Iguchi T, Hanaoka Y, Mikamid H (2006) Ecotoxicol Environ Saf 63:236-243

14. Hu F, Smith EE, Carr JA (2007) Gen Comp. Endocrinol., DOI 10.1016/j.ygcen.2007.04.015

15. Kloas W, Lutz I, Einspanier R (1999) Sci Total Environ 225:59-68

16. Pickford DB, Hetheridge MJ, Caunter JE, Hall AT, Hutchinson TH (2003) Chemosphere 53:223-235

17. Levy G, Lutz I, Krueger A, Kloas W (2003) Environ Res 94:102-111

18. Tavera-Mendoza L, Ruby S, Brousseau P, Fournier M, Cyr D, Marcogliese D (2002) Environ Toxicol Chem 21:527-531

19. Tavera-Mendoza L, Ruby S, Brousseau P, Fournier M, Cyr D, Marcogliese D (2002) Environ Toxicol Chem 21:1264-1267

20. Hayes TB, Collins A, Lee M, Mendoza M, Noriega N, Stuart AA, Vonk A (2002) Proc Natl Acad Sci USA 99:5476-5480

21. Hayes T, Haston K, Tsui M, Hoang A, Haeffele C, Vonk A (2003) Environ Health Perspect 111:568-575

22. Carr JA, Gentles A, Smith EE, Goleman WL, Urquidi LJ, Thuett K, Kendall RJ, Giesy JP, Gross TS, Solomon KR, Van der Kraak GL (2003) Environ Toxicol Chem 22:396-405

23. Jooste AM, Du Preez LH, Carr JA, Giesy JP, Gross TS, Kendall RJ, Smith EE, Van der Kraak GL, Solomon KR (2005) Environ Sci Technol 39:5255-5261
24. EPA, 2003a EPA White Paper on Potential Developmental Effects of Atrazine on Amphibians. Submitted to the FIFRA Scientific Advisory Panel, June 17, 2003 (http://www.epa.gov/scipoly/sap/ 2003/june/finaljune2002telconfreport.pdf).

25. Nieuwkoop and Faber (1994) Garland Publishing, New York, NY

26. De Boever P, Demare W, Vanderperren E, Cooreman K, Bossier P, Verstraete W (2001) Environ Health Perspect 109:691-697

27. Thomas KV, Hurst MR, Matthiessen P, McHugh M, Smith A, Waldock MJ (2002) Environ Toxicol Chem 21:1456-1461

28. ASTM, American Society for Testing Materials (ASTM) (2003) Standard guide for conducting Acute toxicity tests on test material with fishes, macroinvertebrates, and amphibians. ASTM Designation E729-96, March 2003, 22 pp

29. Greenberg A (1999) Standard Methods for the Examination of Water and Wastewater. American Water Works Association. P. 1220

30. Kloas W, Lutz I (2006) J Chromatogr A 1130:16-27

31. Villalpando I, Merchant-Larios H (1990) Int J Dev Biol 34:281285

32. Witschi E, Allison J (1950) Anat Rec 108:589-590

33. EPA, FIFRA SAP. SAP Report No. 2003-01. Report:FIFRA Scientific Advisory Panel Meeting. June 17-20, 2003b, held at the Crowne Plaza Hotel, Arlington, Virginia. A Set of Scientific Issues Being Considered by the Environmental Protection Agency Regarding: Potential Developmental Effects of Atrazine on Amphibians. (http://www.epa.gov/scipoly/sap/2003/june/junemeet ingreport.pdf

34. Hayes TB, Licht P (1993) Gen Comp Endocrinol 91:250-258

35. Coady KK, Murphy MB, Villeneuve DL, Hecker M, Jones PD, Carr JA, Solomon KR, Smith EE, Van der Kraak GL, Kendall RJ, Giesy JP (2005) Ecotoxicol Environ Saf 62:160-173

36. Cong L, Qin Z-F, Jing X-N, Yang L, Zhou J-M, Xu X-B (2006) Aquat Toxicol 77:250-256

37. Hecker M, Giesy JP, Jones PD, Jooste AM, Carr JA, Solomon KR, Smith EE, Van der Kraak GL, Kendall RJ, du Preez L (2004) Environ Toxicol Chem 1996-2007

38. Bogi C, Levy G, Lutz I, Kloas W (2002) Comp Biochem Physiol B 133:559-570

39. Hecker M, Murphy MB, Coady KK, Villeneuve DL, Jones PD, Carr JA, Solomon KR, Smith EE, Van der Kraak GL, Gross T, du Preez L, Kendall RJ, Giesy, JP (2006) Rev Environ Contam Toxicol 103-131 